\title{
ANN-Based Estimation of Low-Latitude Monthly Ocean Latent Heat Flux by Ensemble Satellite and Reanalysis Products
}

\author{
Xiaowei Chen ${ }^{1}$, Yunjun Yao ${ }^{1, *}{ }^{1}$, Yufu Li ${ }^{2}$, Yuhu Zhang ${ }^{3}$, Kun Jia ${ }^{1}{ }^{\mathbb{D}}$, Xiaotong Zhang ${ }^{1}$, \\ Ke Shang ${ }^{1 \oplus}$, Junming Yang ${ }^{1}$, Xiangyi Bei ${ }^{1} \mathbb{D}$ and Xiaozheng Guo ${ }^{1}$ \\ 1 State Key Laboratory of Remote Sensing Science, Faculty of Geographical Science, Beijing Normal University, \\ Beijing 100875, China; chen_xiaowei@mail.bnu.edu.cn (X.C.); jiakun@bnu.edu.cn (K.J.); \\ xtngzhang@bnu.edu.cn (X.Z.); shangke@mail.bnu.edu.cn (K.S.); julming@mail.bnu.edu.cn (J.Y.); \\ xiangyibei@mail.bnu.edu.cn (X.B.); boyxiaozheng@mail.bnu.edu.cn (X.G.) \\ 2 Jincheng Meteorological Administration, Jincheng 048026, China; qxtlyf@163.com \\ 3 College of Resource Environment and Tourism, Capital Normal University, Beijing 100048, China; \\ yuhu.zhang@cnu.edu.cn \\ * Correspondence: yaoyunjun@bnu.edu.cn; Tel.: +86-10-5880-3002
}

Received: 9 July 2020; Accepted: 21 August 2020; Published: 24 August 2020

\begin{abstract}
Ocean latent heat flux $(L H F)$ is an essential variable for air-sea interactions, which establishes the link between energy balance, water and carbon cycle. The low-latitude ocean is the main heat source of the global ocean and has a great influence on global climate change and energy transmission. Thus, an accuracy estimation of high-resolution ocean LHF over low-latitude area is vital to the understanding of energy and water cycle, and it remains a challenge. To reduce the uncertainties of individual $L H F$ products over low-latitude areas, four machine learning $(M L)$ methods (Artificial Neutral Network $(A N N)$, Random forest $(R F)$, Bayesian Ridge regression and Random Sample Consensus (RANSAC) regression) were applied to estimate low-latitude monthly ocean $L H F$ by using two satellite products (JOFURO-3 and GSSTF-3) and two reanalysis products (MERRA-2 and ERA-I). We validated the estimated ocean $L H F$ using 115 widely distributed buoy sites from three buoy site arrays (TAO, PIRATA and RAMA). The validation results demonstrate that the performance of $L H F$ estimations derived from the $M L$ methods (including $A N N, R F, B R$ and $R A N S A C$ ) were significantly better than individual $L H F$ products, indicated by $R^{2}$ increasing by $3.7-46.4 \%$. Among them, the $L H F$ estimation using the ANN method increased the $R^{2}$ of the four-individual ocean $L H F$ products (ranging from 0.56 to 0.79 ) to 0.88 and decreased the RMSE (ranging from 19.1 to 37.5 ) to $11 \mathrm{~W} \mathrm{~m}^{-2}$. Compared to three other $M L$ methods (RF, BR and RANSAC), ANN method exhibited the best performance according to the validation results. The results of relative uncertainty analysis using the triangle cornered hat (TCH) method show that the ensemble LHF product using ML methods has lower relative uncertainty than individual LHF product in most area. The ANN was employed to implement the mapping of annual average ocean $L H F$ over low-latitude at a spatial resolution of $0.25^{\circ}$ during 2003-2007. The ocean $L H F$ fusion products estimated from $A N N$ methods were $10-30 \mathrm{~W} \mathrm{~m}^{-2}$ lower than those of the four original ocean products (MERRA-2, JOFURO-3, ERA-I and GSSTF-3) and were more similar to observations.
\end{abstract}

Keywords: latent heat flux (LHF); artificial neutral network; machine learning methods; triangle cornered hat 


\section{Introduction}

Ocean latent heat flux $(L H F)$ plays a key role in the transformation of energy and vapor at the interface of the atmosphere and ocean [1-3]. Knowledge of ocean turbulent fluxes is important for understanding the mechanism of global heat and freshwater budget and is helpful in various research, including on atmospheric issues, oceanic problems and weather prediction. The study of sea-air heat flux can deepen the understanding of the ocean circulation driving model, elucidate the role of the ocean in balancing global energy and develop numerical prediction work on climate change. Both the atmospheric model and the ocean model require accurate $L H F$ estimates for numerical simulation and forecasting [4-7]. Thus, accurate LHF estimation of low-latitude regions is essential for climate and hydrology applications. Among them, ocean LHF in low-latitude regions has an important impact on global climate change.

Low-latitude areas within $30^{\circ} \mathrm{N}$ to $30^{\circ} \mathrm{S}$, including tropical and subtropical regions, account for approximately half of the Earth's surface area. Because it is covered by the ocean and receives concentrated solar radiation, low-latitude areas store a large amount of water vapor and heat. The LHF transferred from low-latitude oceans to the atmosphere is the main source of atmospheric circulation energy [8-10]. Thus, accurate LHF estimation of low-latitude areas plays a key role in climate and hydrology applications [11]. Accurate estimation of high spatial resolution ocean LHF is vital for researching climate change, and it remains a challenge.

Continuous ocean LHF monitoring is mainly located in low-latitude areas, which can improve the accuracy of ocean LHF estimates. Many experiments have been carried out to promote the study of air-sea turbulent fluxes [12-15], such as the Global Energy and Water Cycle Experiment (GEWEX) [16] and Joint Global Ocean Flux Study (JGOFS) [17]. Based on a large amount of experimental observations, the parameterization scheme of the turbulence flux algorithm has developed rapidly, and global ocean turbulence flux products with different scales and spatial and temporal resolutions have been produced. Satellite and reanalysis data can provide us with spatially and temporally continuous ocean LHF observations at various scales. At present, various satellite and reanalysis LHF products with moderate or coarse spatial resolution have been produced, including Japanese Ocean Flux Data Sets with Use of Remote Sensing (J-OFURO) [18], Goddard Satellite-Based Surface Turbulent Fluxes (GSSTF-3) [19], the Hamburg Ocean Atmosphere Parameters and Fluxes from Satellite Data (HOAPS) [20], Modern-Era Retrospective analysis for Research and Applications (MERRA), ERA_Interim, etc. However, compared with the observations obtained from buoy sites or experimental ships, satellite-based LHF products present large discrepancies. Brunke et al. [21] concluded that satellite-based products have generated large uncertainty in the process of inversion by comparing various turbulent flux products and four satellite products (GSSTF2, GSSSF2b, J-OFURO and HOAPS). Some satellite-based products provide accurate LHF estimates, but the study areas are limited to specific areas (e.g., SCS). Reanalysis products provide us with reasonable estimations of ocean LHF and have been successfully used in numerical weather prediction (NWP); however, they have notable errors owing to data assimilation schemes. Some reanalysis has a relatively high spatial and temporal resolution but tend to overestimate ocean $L H F$ in most areas compared to buoy site measurements. Many studies have also indicated that ocean $L H F$ estimates with a coarse spatial resolution (e.g., $1^{\circ}$ ) may lead to large errors due to the spatial heterogeneity of ocean LHF [22].

Over the last forty years, many methods have been developed to implement ocean LHF estimates. To date, the methods used for estimating ocean LHF can be calculated by: (1) physically-based methods [23-25]; (2) data assimilation methods [26-30]; and (3) bulk aerodynamic algorithms [31-34]. Physically-based methods, including eddy covariance methods and inertial dissipation methods [35-38], are considered the most reliable methods in estimating ocean LHF. However, these methods require high-frequency instruments that can only be implemented for site-scale observations; further, such observations are limited in temporal and spatial distribution. Data assimilation methods can provide a reasonable simulation of the ocean $L H F$, but the difference in the parameterization scheme may introduce significant uncertainty to ocean LHF estimations [39-41]. 
Widely used bulk aerodynamic algorithms utilize air temperature, sea surface temperature, air specific humidity and wind speed as input bulk quantities to calculate ocean turbulent fluxes. Even though these methods can be used everywhere on Earth, there are still significant uncertainties from different models $[23,42,43]$. These methods are widely used to estimate ocean LHF at various temporal and spatial resolutions. However, the ocean LHF estimates derived from these methods differ substantially from observations [44-46].

Recently, multiple product ensembles using machine learning $(M L)$ methods have been successfully applied to estimate terrestrial latent heat flux $(L E)$. For example, Yao et al. [47] used support vector machine (SVM) to integrate three satellite-based $L E$ products to improve global terrestrial evapotranspiration (ET) estimation and found that the SVM method was superior to all other physical methods. Fan et al. [48] developed four tree-based ensemble models (RF, M5Tree, GBDT and XGBoost) to estimate daily ET using limited meteorological data; the developed XGBoost and GBDT models have accurate predictions, strong model stability and low calculation cost. Shang et al. [49] applied four ML methods (Extremely Randomized Trees (ETR), Gradient Boosting Regression Tree (GBRT), Random Forest $(R F)$ and Gaussian Process Regression (GPR)) to improve terrestrial LE estimations over Europe based on five individual terrestrial $L E$ product; the validation results illustrate that the $L E$ estimation using ETR method increased $R^{2}$ and decreased $R M S E$. Even though the $M L$ methods have been widely used to estimate terrestrial biophysical variables, there is a lack of experiments on dataset fusion to improve ocean $L H F$ estimates by combining multiple $L H F$ products.

In this study, we used the Artificial Neutral Network (ANN) method to improve ocean LHF estimation over low-latitude areas by using four individual LHF products. We had three objectives: (1) evaluate the performance of the $A N N$ and three other $M L$ methods $(R F$, Bayesian Ridge Regression $(B R)$ and Random Sample Consensus (RANSAC)) by using four LHF products based on the moored buoy array of TAO, the Research Moored Array for African-Asian-Australian Monsoon Analysis and Prediction (RAMA) and the Prediction and Research Moored Array in the Tropical Atlantic (PIRATA); (2) assess the relative uncertainties among of the ocean $L H F$ products based on the triangle cornered hat $(T C H)$ method; and (3) use ANN to map the average ocean $L H F$ with $0.25^{\circ}$ spatial resolution for the period of 2003-2007 by using an ensemble of four LHF products.

\section{Data}

\subsection{Satellite and Reanalysis Ocean LHF Products}

The LHF products used in this study include the following: MERRA-2 [50], European Centre for Medium-Range Weather Forecasts (ECMWF) interim reanalysis (ERA-I) [51], Japanese Ocean Flux Data Sets with Use of Remote Sensing (J-OFURO) [18] and Goddard Satellite-Based Surface Turbulent Fluxes (GSSTF-3) [19].

Monthly ocean latent heat flux estimates derived from MERRA-2 [52], with a spatial resolution of $0.5^{\circ}$ latitude $\times 0.625^{\circ}$ longitude, from January 2003 to December 2007, was launched aboard the EARTHDATA at https://earthdata.nasa.gov/. The ERA-I data [53] were produced by the data assimilation system using 4-dimensional variational assimilation (4D-Var), with a spatial resolution of $0.25^{\circ}$ latitude $\times 0.25^{\circ}$ longitude. J-OFURO was produced by the School of Marine Science and Technology at Tokai University and was calculated by the COARE 3.0 method with an improved spatial resolution of $0.25^{\circ}$. Compared to the previous versions, GSSTF-3 is an improved version with corrected surface specific humidity (Qair) data retrieved by removing the effect of the Earth incidence angle (EIA) drifting [23]. These data were obtained from Goddard Earth Science Data and Information Services Center's (GES DISC) website, with an advantage of a high spatial resolution of $0.25^{\circ}$.

The objectively analyzed air-sea fluxes product $(O A F l u x)[6,54]$ was used to validate the accuracy of the fusion product. It has been reported that the OAFlux dataset is a reliable product for ocean turbulent flux research. The OAFlux data have an advantage in that they combine satellite-derived data and reanalysis data by using the objective analysis method; however, these data have a coarser 
spatial resolution of $1^{\circ}$. To estimate the monthly global ocean $L H F$ products at a spatial resolution of $0.25^{\circ}$ from 2003 to 2007 , we used the bilinear interpolation method. Detailed information for each product mentioned above is summarized in Table 1 and detailed input variable datasets of each $L H F$ product is summarized in Table 2.

Table 1. Summary of the five ocean LHF products in this study for 2003-2007.

\begin{tabular}{ccccc}
\hline Products & Variables & Spatial Resolution & Time Span & References \\
\hline MERRA-2 & LHF & $1 / 2^{\circ} \times 2 / 3^{\circ}$ & 1980 -present & Rienecker et al., 2011 \\
ERA-interim & LHF & $0.125^{\circ}$ & $1979-$ present & Dee et al., 2011 \\
GSSTF-3 & LHF & $0.25^{\circ}$ & $1987-2008$ & Shie 2012 \\
J-OFURO & LHF & $0.25^{\circ}$ & $1988-2013$ & Tomita et al., 2018 \\
OAFLUX & LHF & $1^{\circ}$ & $1958-$ present & Yu et al., 2004 \\
\hline
\end{tabular}

Table 2. Summary of input variable datasets for each $L H F$ product.

\begin{tabular}{|c|c|c|}
\hline Product & Variable & Source \\
\hline \multirow{5}{*}{ MERRA-2 } & Surface winds & SSM/I; QuikSCAT; ERS (ERS-1 and ERS-2); \\
\hline & Rain rate & SSM/I; TRMM Microwave Imager (TMI); \\
\hline & Radiances & $\begin{array}{l}\text { SSM/I; GOES sounder; TIROS Operational Vertical } \\
\text { Sounder (TOVS) and Advanced TOVS (ATOVS); AIRS; } \\
\text { MSU; AMSU-A; }\end{array}$ \\
\hline & Upper-level winds & geostationary satellites and MODIS \\
\hline & ozone & SBUV \\
\hline \multirow{7}{*}{ ERA-I } & $\begin{array}{l}\text { Surface winds; } \\
\text { Ocean wave height }\end{array}$ & ERS (ERS-1 and ERS-2); \\
\hline & Radiances & $\begin{array}{l}\text { VTPR; High Resolution Infrared Sounder (HIRS); } \\
\text { Stratospheric Sounding Unit (SSU); MSU; AMSU-A; }\end{array}$ \\
\hline & Upper-level winds & Meteosat-2 \\
\hline & Ozone profiles & SBUV \\
\hline & clear-sky radiances & Meteosat-2 \\
\hline & $\begin{array}{l}\text { Surface wind speed; } \\
\text { Column water vapor }\end{array}$ & $\mathrm{SSM} / \mathrm{I}$ \\
\hline & radio occultation $(\mathrm{RO})$ & CHAMP; COSMIC; GRACE \\
\hline \multirow{4}{*}{ GSSTF-3 } & wind speed (U) & $\mathrm{SSM} / \mathrm{I}$ \\
\hline & surface air specific humidity (Qair) & corrected SSM/I brightness temperature $(\mathrm{Tb})$ \\
\hline & Radiances & SIRS, HIRS, VTPR, and TOVS; \\
\hline & Upper-level winds & geostationary satellites \\
\hline \multirow{3}{*}{ JOFURO-3 } & wind speed (U) & $\begin{array}{l}\text { SSM/I; TMI; WindSAT; AMSR-E; AMSR2; ERS (ERS-1 } \\
\text { and ERS-2); QuikSCAT; ASCAT-A; ASCAT-B; OSCAT }\end{array}$ \\
\hline & Qair & SSM/I; TMI; AMSR-E; AMSR2 \\
\hline & SST & $\begin{array}{l}\text { MGDSST; OSTIA-NRT; AMSR-E; MW; OISST; AMSR; } \\
\text { TMI; WindSAT; GMI; OSTIA-RA }\end{array}$ \\
\hline \multirow{3}{*}{ OAFlux } & wind speed (U) & SSM/I; AMSR-E; QuikSCAT; \\
\hline & Qair & SSM/I; \\
\hline & SST & NCEP-OI; NCEP-NCAR; NCEP-DOE; ERA-40 \\
\hline
\end{tabular}




\subsection{Buoy Observations}

Buoy observations were used as the reference data to evaluate the performance of the ocean LHF estimation. The monthly ocean latent heat observations were collected from 115 moored buoy sites [55-58].

Among 115 moored buoy sites, 67 buoys were collected from the Tropical Atmosphere Ocean/Triangle Trans Ocean Buoy Network (TAO/TRITON, https://tao.ndbc.noaa.gov/), 18 buoys were collected from the Prediction and Research Moored Array in the Tropical Atlantic (PIRATA, http://www.brest.ird.fr/pirata/) and 12 buoys were collected from the African-Asian-Australian Monsoon Analysis and Prediction (RAMA, https://www.pmel.noaa.gov/tao/drupal/disdel/). All ocean turbulent fluxes were calculated by the COARE 3.0 method; these data covered the period from 2003 to 2007. Buoy observations were mainly located in tropic areas. Figure 1 shows buoy site locations and information about the three buoy site arrays. Although the moored buoy footprints varied from the pixel size of the reanalysis and satellite-based products, we still regarded the buoy site observations as "ground truth" in this study.

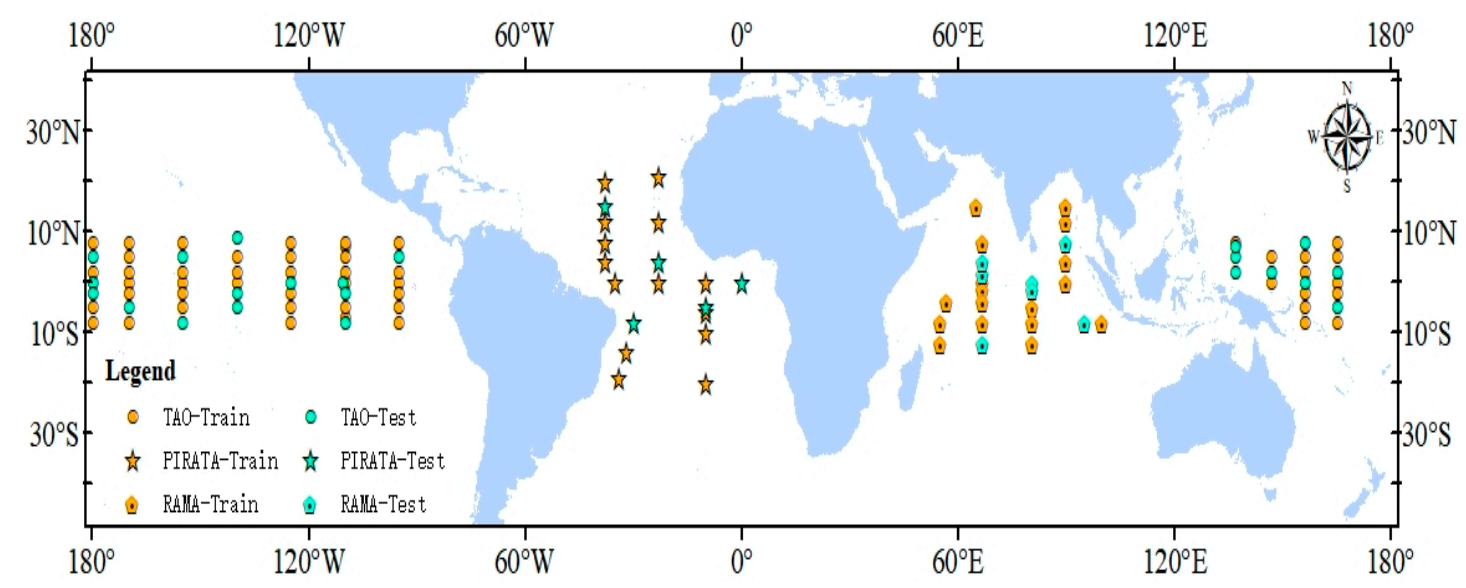

Figure 1. Distribution of 115 buoys sites for different buoy sites arrays over low-latitude area. "Train" represents training sites and "Test" represents the validation sites.

\section{Methods}

\subsection{Artificial Neural Network}

An Artificial Neutral Network (ANN) [59] can be considered a network that consists of a series of adaptive connected simple neuron nodes to simulate the human biological nervous system in response to input signals (Figure 2). Different from logistical regression, which is composed of an input and an output layer, the $A N N$ comprises three layers: the input layer, the hidden layer and the output layer. Various datasets are considered the input data; the input data are weighted in the hidden layer by means of flexible mathematical algorithms, and the prediction dataset is produced in the output layer. Based on self-adaptation and self-learning, the ANN method causes the input and output data to establish a nonlinear relationship.

Within the hidden layer, the fully connected neurons receive input signals from other neurons; these input signals are passed through a weighted connection.

$$
y_{j}=\sum_{n=1}^{m} w_{n j} b_{n}
$$

where $y_{j}$ refers to the $j$ th neuron output data, $w_{n j}$ is the connection weight of the $n$th neuron in the hidden layer and the $j$ th output layer neuron and $b_{n}$ is the output of the nth neuron in the hidden layer. 
The total input signal value received by the different neurons is used to compare with the threshold of the neuron node,

$$
y_{j}=f\left(\beta_{j}-\theta_{j}\right)
$$

where $f$ is the activation function of the neural network, $\beta_{j}$ is the output received by the $j$ th neuron in the output layer and $\theta_{j}$ is the threshold of the $j$ th neuron in the output layer.

Then, the output data of the neuron are easily generated by the activation function. The learning process of ANN is used to adjust the connection weight between neurons and the threshold of each neuron based on the results of the training data.

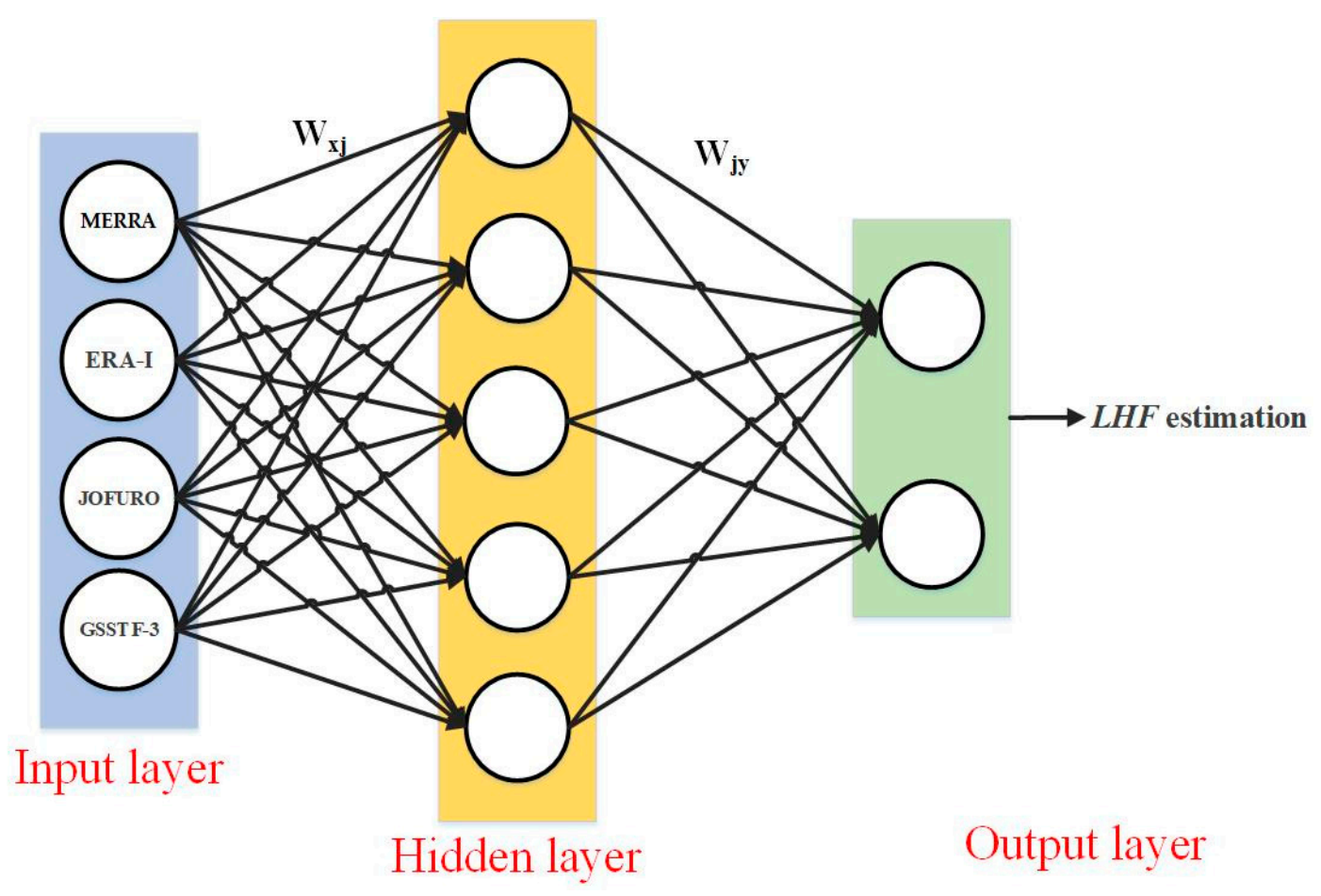

Figure 2. The structure of Artificial neural network (ANN) algorithm.

\subsection{Other Machine Learning Methods}

\subsubsection{Random Forest}

$R F[59]$ is an ensemble method that is widely applied for regression issues. It uses classification regression tree $(C A R T)$ as a regressor for the decision tree and bootstrap sample methods to select different training datasets for different decision trees. Further, it randomly selects features to perform attribute splitting on internal nodes when constructing a single tree. Therefore, the RF method can better exclude noise interference and has better performance for classification and regression. Generalization is the ability of the Random Forest to correctly predict data outside the training set, and the generalization error is the probability of a misclassification of the data outside the training set by the regression. The generalization error of a Random Forest depends on the regression ability of a single tree and the correlation between any two trees. Research results show that the generalization error of the RF converges to a finite value; thus, as the number of classification trees in the forest increases, the Random Forest does not cause overfitting.

\subsubsection{Bayesian Ridge Regression}

In addition to the RF and $A N N$ methods, we also applied two other linear regression methods to predict ocean LHF flux. Compared to other $M L$ methods, the linear regression method is fast in 
modeling, and the calculation method is simple. Therefore, even if the amount of input data is large, the calculation speed is fast.

Considering the high correlation among the input variables in this paper, we used the Bayesian Ridge Regression (BR) [60] to estimate ocean LHF flux. Generally, the linear regression algorithm uses the least squares method to optimize the coefficients. Ridge regression obtains the optimal parameters by penalizing the coefficients to reduce the impact of highly correlated input variables. The Bayesian Ridge Regression (BR) method, which combines the Bayesian method and the ridge regression method, has a strong self-adaptation ability to the input datasets, which not only avoids the overfitting of datasets but also promotes a high utilization rate of data samples.

\subsubsection{Random Sample Consensus}

The RANSAC regression [61] model can obtain valid sample data from the observation dataset containing "outliers" and iteratively estimate the mathematical model parameters. In short, the RANSAC method process is as follows: first, randomly extracted samples from the datasets build "interior points"; second, the remaining datasets test the model training by "interior points" and add the sample points that fall within a predetermined tolerance range to the "interior points"; finally, it fits the model with all the "interior points" and uses "interior points" to estimate the error. The process is terminated if the model performance reaches expectations.

\subsection{Triangle Cornered Hat Method}

$T C H$ [62] can estimate relative uncertainty without prior knowledge. The TCH method is an improved version of the Triangle Cornered (TC) method and can be used to calculate the relative uncertainty among three or more independent products. Quantifying uncertainty by removing "true values" from different variables (assuming the input variables all contain true values) is a difference method. This method has been successfully used in gravity fields [63], evapotranspiration [64] and soil moisture [65] at different scales. Here, we applied the $\mathrm{TCH}$ method to quantify the relative uncertainty among ocean heat fluxes from different products.

The TCH method treats the time series of input products as $\left\{X_{i}\right\}, i=1,2, \ldots, N$. The subscript $i$ represents the $i$ th product among all sorted products and $N$ represents the total number of products. $\left\{X_{i}\right\}$ can be divided into two parts, including the "true value" $\left\{X_{t}\right\}$ and the error term $\left\{\varepsilon_{i}\right\}$ :

$$
X_{i}=X_{t}+\varepsilon_{i}, \forall_{i}=1,2, \ldots, N
$$

Due to an unknown true value, it is difficult to obtain the error term $\left\{\varepsilon_{i}\right\}$. Thus, the first step in the TCH method is to determine the difference among the $N$ products and reference dataset. First, choose one time series LHF product as reference data $\left\{X_{R}\right\}$ and calculate the differences $\left\{D_{i, M}\right\}$ between reference data $\left\{X_{R}\right\}$ and other LHF datasets $\left\{X_{i}\right\}$.

$$
D_{i, M}=X_{i}-X_{R}=\varepsilon_{i}-\varepsilon_{R} \forall_{i i}=1,2, \ldots, N-1
$$

where $D_{i, M}$ represent the difference matrix between the reference dataset $\left\{X_{R}\right\}$ and the input dataset $\left\{X_{i}\right\}$. Next, calculate the $(N-1) \times(N-1)$ covariance matrix $S=\operatorname{cov}(D)$ and determine the covariance matrix of the noise matrix $G$ through the $S$ matrix:

$$
\begin{aligned}
& \mathrm{S}=M^{T} \cdot G \cdot M \\
& \mathrm{M}=\left[\begin{array}{c}
A \\
-u^{T}
\end{array}\right]
\end{aligned}
$$

where $A$ is the identity matrix and $u$ is the vector of $\left[\begin{array}{llll}1 & 1 & \ldots\end{array}\right]$. To minimize the global correlation of errors, Premoli and Tavella [66] proposed a free parameter selection criterion to maintain the positive definiteness of $G$. According to the constraint minimization problem proposed by the Kuhn-Tucker 
theorem, it can be used to determine the unique solution of the matrix $G$, and the random error of each group of data can be calculated.

\subsection{Evaluation Metrics}

The squared correlation coefficient $\left(R^{2}\right)$, root-mean-square-error (RMSE) and bias are used as metrics to evaluate the performance of the LHF estimations against reference dataset. The matching degree between the evaluated estimations $\left\{x_{i}\right\}$ and the reference dataset $\left\{r_{i}\right\}$ can be judged by the metrics mentioned above, and they are written as:

$$
\begin{gathered}
R^{2}=\frac{\left(\sum_{i=1}^{N}\left(x_{i}-\bar{x}\right)\left(r_{i}-\bar{r}\right)\right)^{2}}{\sum_{i=1}^{N}\left(x_{i}-\bar{x}\right)^{2} \sum_{i=1}^{N}\left(r_{i}-\bar{r}\right)^{2}} \\
\text { Bias }=\frac{\sum_{i=1}^{N}\left(x_{i}-r_{i}\right)}{N} \\
\text { RMSE }=\sqrt{\frac{1}{n} \sum_{i=1}^{N}\left(x_{i}-r_{i}\right)^{2}}
\end{gathered}
$$

where $N$ represents the number of samples. The King-Gupta efficiency (KGE) is a comprehensive evaluation metric that can be calculated as follows:

$$
K G E=1-\sqrt{(R-1)^{2}+\left(\frac{S T_{e}}{S T_{o}}-1\right)^{2}+\left(\frac{E_{e}}{E_{o}}-1\right)^{2}}
$$

where $R$ denotes the correlation coefficient between the LHF estimation and reference dataset; $S T_{e}$ and $S T_{o}$ represent the standard deviation of the LHF estimation and reference dataset, respectively; and $E_{e}$ and $E_{o}$ are the mean value of the $L H F$ estimation and reference dataset, respectively. The closer KGE is to 1 , the closer the LHF estimation is to the reference dataset.

\subsection{Experimental Setup}

Before model construction, we extracted $L H F$ variable from four products and in situ measurements. More than 4000 observations from 115 buoy sites were collected as target variable, and LHF variable extracted from four products (JOFURO-3, GSSTF-3, ERA-I and MERRA-2) were used as predictor variables. To build the model, the datasets (both target dataset and predictor dataset) were randomly divided into two groups: $70 \%$ to train the model and the remaining $30 \%$ to validate the trained model. The best parameters which can provide the highest correlation coefficient were selected in the training data through cross validation. The obtained optimal parameters were then used in the model to estimate LHF.

We constructed the $A N N, R F, B R$ and $R A N S A C$ model based on sklearn modules by using the Python platform. The main parameters of $A N N$ models include the learning_rate, hidden_layer_sizes, n_estimators and min_samples_split. The performance of $R F$ method in the scikit-learn toolbox is mainly influenced by $n \_$estimators and max-features. The main parameters of $B R R$ are $\mathrm{n} \_$iter and lambda. The main parameters to adjust when using RANSAC are max_trials, min_samples and residual_threshold. Obtaining the optimal parameters of the model can not only improve the accuracy of model estimation but also improve efficiency and shorten model running time.

To find the optimal parameter for each $M L$ method, we applied the GridSearchCV module. GridSearchCV method is a parameter tuning method. It tries every possibility through loop traversal among all parameter combinations and selects the optimal parameter combination based on the performance of the results. The main disadvantage of this method is that it is time-consuming. 
Optimal parameter combinations for each $M L$ methods were determined by GridSearchCV method in optional parameters, as shown in Table 3.

Table 3. Parameters setting to determine the optima parameters for $M L$ methods.

\begin{tabular}{|c|c|c|c|c|}
\hline Method & Parameters & Optional & Interval & $\begin{array}{l}\text { Selection of } \\
\text { GridSearchCV }\end{array}$ \\
\hline \multirow{4}{*}{$A N N$} & activation & "identity", "logistic", “tanh", "relu” & - & relu \\
\hline & learning_rate & $\begin{array}{l}\text { “10", “1”, “0.1”, “0.01”, } \\
\text { “0.001”, “0.0001” }\end{array}$ & - & 0.01 \\
\hline & hidden_layer_sizes & 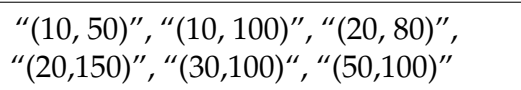 & - & $(20,80)$ \\
\hline & batch_size & $50-300$ & 50 & 150 \\
\hline \multirow{3}{*}{$R F$} & min_samples_split & $2-6$ & 1 & 4 \\
\hline & n_estimators & $5-50$ & 3 & 40 \\
\hline & max-features & $1-10$ & 1 & 6 \\
\hline \multirow[b]{2}{*}{$B R$} & n_iter & $20-300$ & 20 & 240 \\
\hline & lambda & $\begin{array}{l}\text { “0.1”, “0.01”, “0.001”, “0.0001” } \\
\text { “0.00001”, “0.000001”, } \\
\text { “0.0000001” }\end{array}$ & - & “0.000001” \\
\hline \multirow{3}{*}{ RANSAC } & max_trials & $30-120$ & 5 & 105 \\
\hline & min_samples & $80-300$ & 20 & 260 \\
\hline & residual_threshold & $5-100$ & 5 & 45 \\
\hline
\end{tabular}

\section{Results}

\subsection{Validation of the Five Ocean LHF Products against Buoy Observations}

At the site scale, the five ocean LHF products exhibited substantial differences in ocean LHF estimation, as shown in Figure 3. For the TAO buoy site array with the most observations, the monthly ocean LHF estimation of ERA-I product correlated best with the observations, indicated by an $R^{2}=0.80$ $(p<0.01)$; however, the RMSE and bias both exceeded $25.2 \mathrm{~W} \mathrm{~m}^{-2}$. Similarly, MERRA also showed good performance with an $R^{2}>0.75(p<0.01)$ but highly overestimated ocean $L H F$ as indicated by the highest RMSE and bias among all ocean LHF products. In contrast, the OAFlux product showed relatively lower $R M S E$ and the lowest bias; the lower correlation $\left(R^{2}=0.56, p<0.01\right)$ may be caused by its coarse spatial resolution (approximately $1^{\circ}$ ). GSSTF-3 performed least satisfactorily in estimating ocean LHF, with disperse distribution of validation points and relatively high overall estimates. Compared to other observation arrays, all ocean LHF products performed better with higher $R^{2}$ and lower bias in the PIRATA buoy site array. 

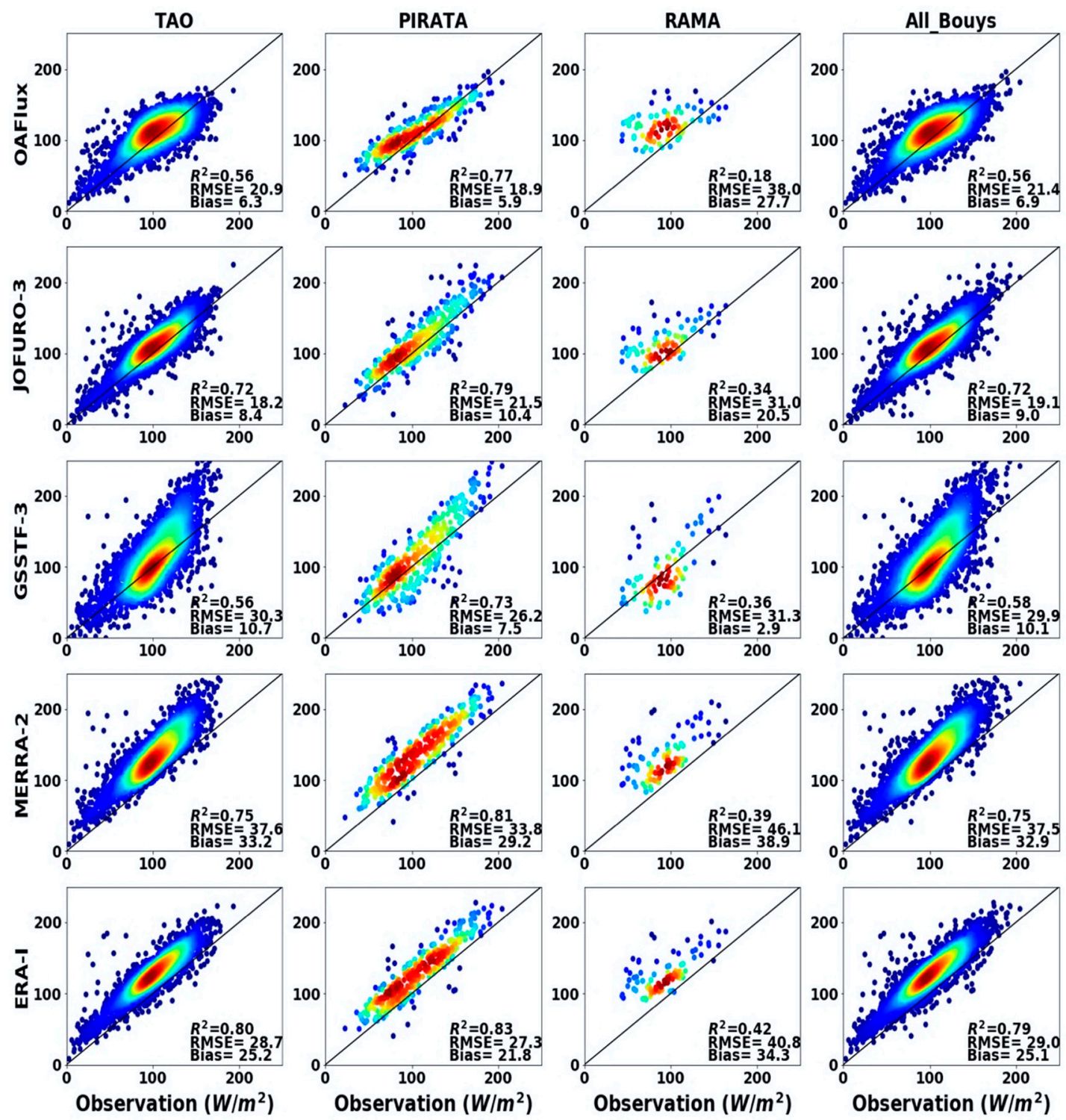

Figure 3. Validation of five products against buoy observations from 115 sites during the period from 2003 to 2007 (unit $\mathrm{W} \mathrm{m}^{-2}$ ).

Figure 4 shows the $R^{2}, R M S E$, bias and KGE statistics of five ocean LHF products against observations from different buoy sites. For all buoy site arrays, reanalysis products (MERRA and $E R A-I$ ) have the highest $R^{2}$ ranging from 0.39 to 0.83 . However, the magnitude of average monthly LHF derived from reanalysis is much higher than that of buoy-measured LHF, as indicated by biases exceeding 25 and $32 \mathrm{~W} \mathrm{~m}^{-2}$, respectively. When considering the KGE (ranging from 0.5 to 0.83 ) and RMSE (ranging from 18 to $31 \mathrm{~W} \mathrm{~m}^{-2}$ ), the JOFURO-3 product is superior to others. This indicates that different parameterizations of ocean $L H F$ products affect the accuracy of ocean $L H F$ estimates. The performance of OAFlux products is lower than JOFURO-3 but better than GSSTF-3; this is probably caused by the coarse spatial resolution of OAFlux, which has a spatial resolution of $1^{\circ}$. 

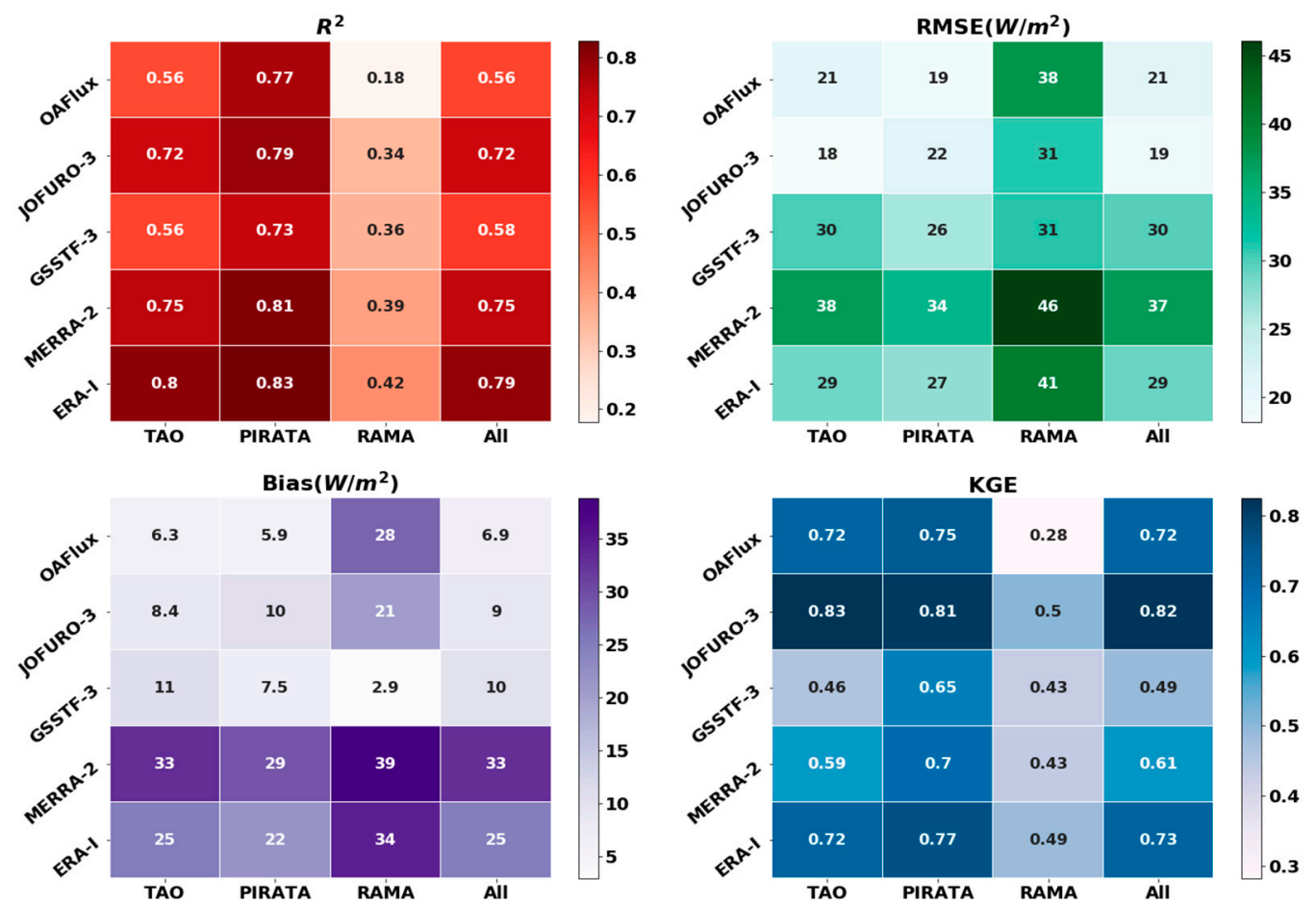

Figure 4. The evaluation parameters $\left(R^{2}, R M S E\right.$, bias and $\left.K G E\right)$ comparison between the five ocean LHF products against buoy sites observations (unit $\mathrm{W} \mathrm{m}^{-2}$ ).

\subsection{Ensemble of Four Ocean LHF Products from ANN and Other ML Methods}

\subsubsection{Model Training and Validation based on Buoy Observations}

None of the individual ocean $L H F$ products provides the best $L H F$ estimates based on buoy observations. Thus, we used $A N N$ and other $M L$ methods (RF, BR and RANSAC) to calculate ocean $L H F$ by an ensemble of four ocean LHF products: MERRA, ERA-I, JOFURO-3 and GSSTF-3. The reanalysis products are highly correlated with measurements but also highly overestimate ocean $L H F$. In contrast, the satellite-based product JOFURO-3 and objectively analyzed product OAFlux perform well with lower bias.

Figure 5 represents the training results of $A N N, R F, B R$ and $R A N S A C$ for all buoy site observations. Estimated ocean $L H F$ derived from four $M L$ methods agreed well with buoy measurements and is consistent with the trend of buoy observations. Among the four $M L$ methods, ANN has the highest $R^{2}$ and lowest RMSE in training datasets, as indicated by an $R^{2}$ exceeding 0.88 . The RANSAC method has a slightly higher RMSE of $12.1 \mathrm{~W} \mathrm{~m}^{-2}$ and a slightly lower $R^{2}$ than other $M L$ methods.

Figure 6 shows the scatter plot for the ocean LHF observations and LHF estimations from four $M L$ methods. The validation results show that $A N N$ yields the best estimations of ocean $L H F$, as indicated by the highest $R^{2}$ of 0.87 , the lowest RMSE of $10.9 \mathrm{~W} \mathrm{~m}^{-2}$ and the highest comprehensive index (KGE) of 0.90 , followed by $R F$ and $B R$. Although RANSAC performed weakly as indicated by the lowest $R^{2}$ (0.82) and KGE (0.78), it is still superior to any individual ocean $L H F$ product. Overall, these results illustrate that the ocean $L H F$ fusion products derived from $M L$ methods are superior to individual $L H F$ products. In addition, the $A N N$ model performs best among the four $M L$ models. 

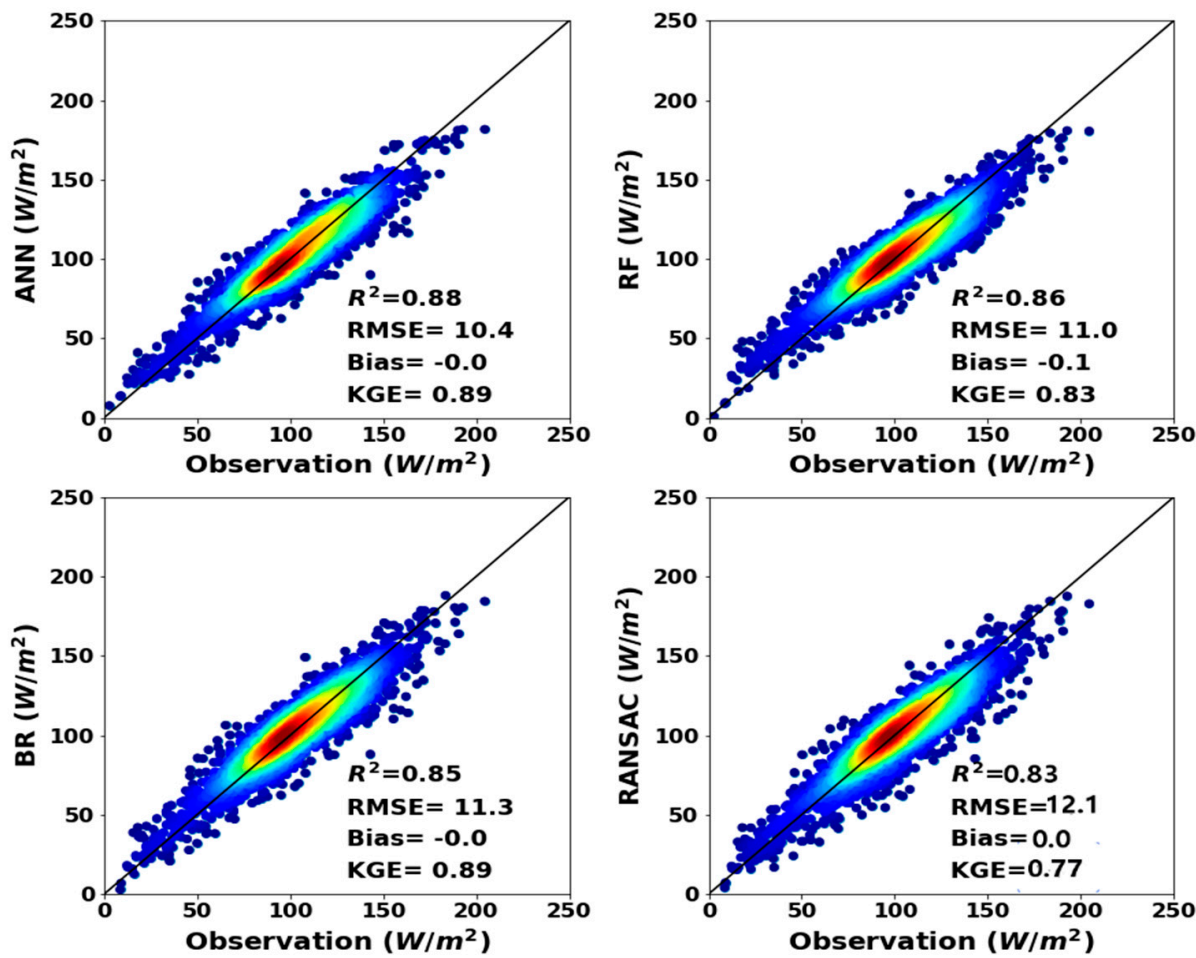

Figure 5. The scatter plots for ocean $L H F$ observations at 81 training buoy sites and LHF estimates from the $A N N, R F, B R$ and RANSAC methods during 2003-2007 (unit $\mathrm{W} \mathrm{m}^{-2}$ ).
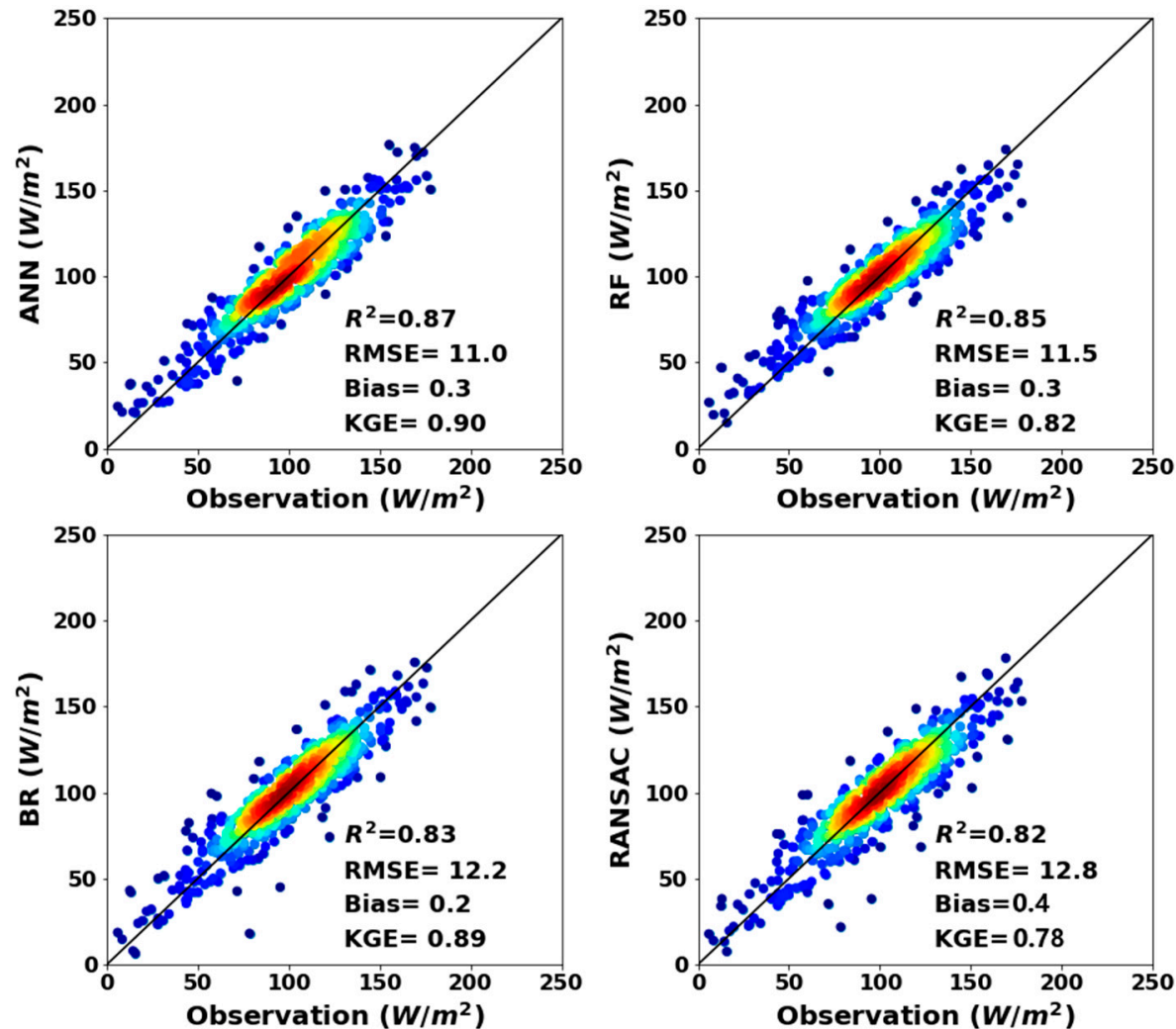

Figure 6. The scatter plot for ocean $L H F$ observations from 34 validation buoy sites and the LHF estimations from the $A N N, R F, B R$ and $R A N S A C$ methods during 2003-2007 (unit $\mathrm{W} \mathrm{m}^{-2}$ ). 


\subsubsection{Relative Uncertainties of Ocean LHF Over Low-latitude Areas}

To quantify the performance of all four methods over the tropics, we used the TCH method to calculate the uncertainties of ocean $L H F$ estimates derived from ML methods.

Figure 7 presents the distribution of relative uncertainties estimated from ocean $L H F$ estimations based on four $M L$ models. Generally, the ocean $L H F$ estimated from $M L$ methods perform better than those from ocean LHF products (MERRA, ERA-I, JOFURO-3 and GSSTF-3). Moreover, the LHF products tend to generate lower uncertainties in the area away from the coast due to the stable and uniform climatic conditions and have higher uncertainties in the area close to land. The $A N N$ and $B R$ perform well over low-latitude areas with lower relative uncertainties; $B R$ has higher uncertainties than $A N N$ in the west of South Africa and equatorial area. Among the LHF estimations based on ML methods, $R F$ has the highest relative uncertainties, especially in the Kuroshio current region and Southern Hemisphere Subtropical area, which may be caused by the errors in the model estimation. For ocean $L H F$ products, although the ERA-I outperforms the other three $L H F$ products, it underperforms the ANN estimation in most areas.
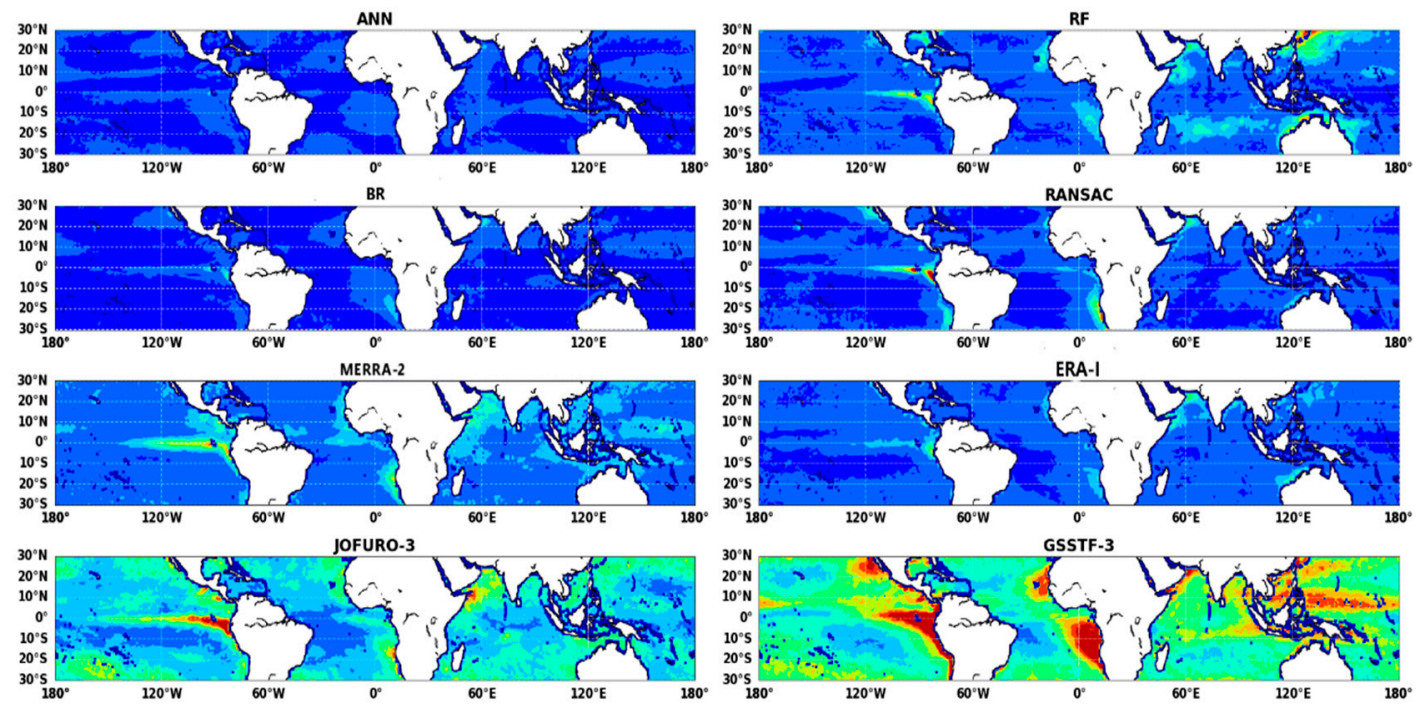

JOFURO-3
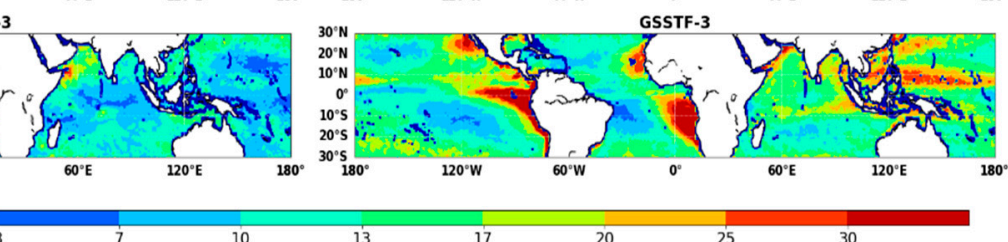

Figure 7. Distribution of relative uncertainties from eight ocean $L H F$ products (including four ocean $L H F$ products and four ensemble $L H F$ products) over low-latitude area (unit $\mathrm{W} \mathrm{m}^{-2}$ ).

Figure 8 shows the relative uncertainties of ocean $L H F$ estimations calculated by four $M L$ methods. $A N N$ outperforms the other $L H F$ estimations with lower average relative uncertainties of $2.60 \mathrm{~W} \mathrm{~m}^{-2}$, a median value of $2.39 \mathrm{~W} \mathrm{~m}^{-2}$ and a maximum of relative uncertainties lower than $10 \mathrm{~W} \mathrm{~m}^{-2}$. The $B R$ is second to $A N N$ with higher average relative uncertainties of $2.86 \mathrm{~W} \mathrm{~m}^{-2}$ and a maximum of relative uncertainties of $20 \mathrm{~W} \mathrm{~m}^{-2}$. Although the median values of relative uncertainties for RF and RANSAC are slightly higher than $A N N$ as indicated by values of 3.15 and 3.95, respectively, they have higher relative uncertainties exceeding $30 \mathrm{~W} \mathrm{~m}^{-2}$.

Overall, ANN slightly outperformed other $M L$ methods according to validation against buoy observations and relative uncertainty evaluation based on the TCH method over tropical areas. 


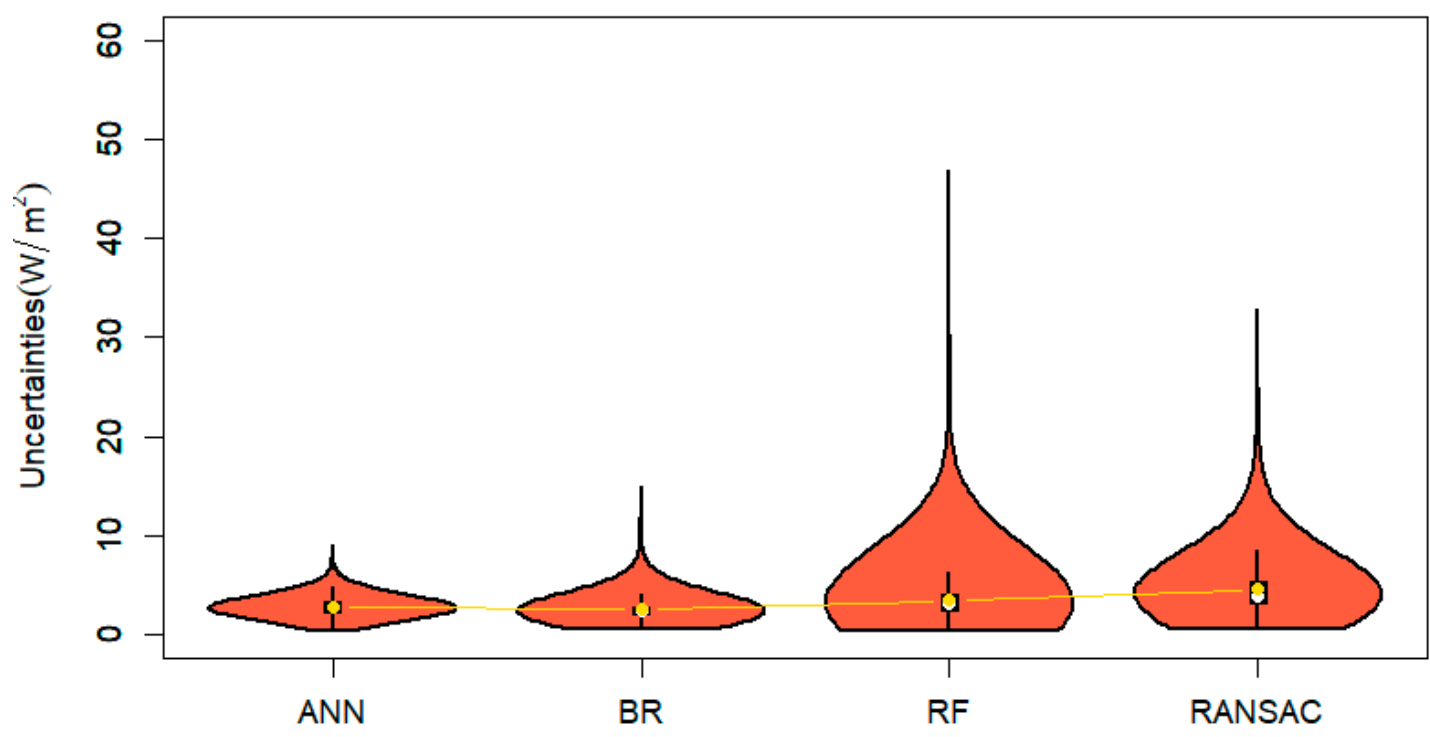

Figure 8. Violin plots of relative uncertainties from four ensemble ocean $L H F$ products over low-latitude area (unit $\mathrm{W} \mathrm{m}^{-2}$ ).

\subsection{Mapping of Ocean LHF Over Low-Latitude Areas}

\subsubsection{Annual Patterns of the Ensemble Tropical Ocean LHF}

We applied $A N N, R F, B R$ and RANSAC driven by monthly ocean $L H F$ products (MERRA-2, JOFURO-3, ERA-I and GSSTF-3) to estimate ocean LHF in low-latitude areas at $0.25^{\circ}$ spatial resolution from 2003 to 2007. Figure 9 shows the spatial distribution of annual LHF averaged from different products during the years 2003-2007.
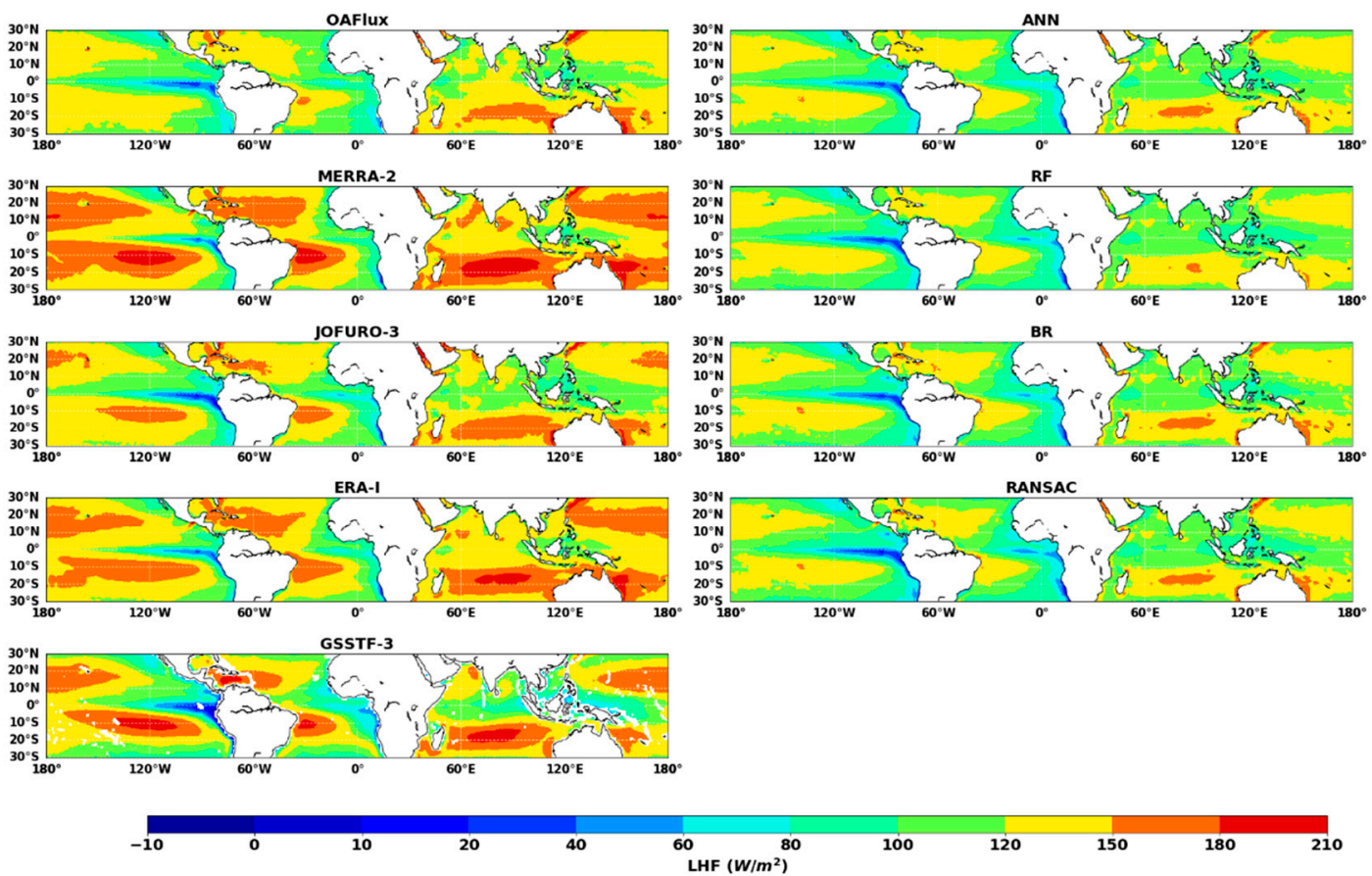

Figure 9. Maps of multi-year (2003-2007) annual average ocean $L H F$. The first column (left) presents the maps of ocean LHF from OAFlux, MERRA-2, JOFURO-3, ERA-I and GSSTF-3. The second column presents the maps of ocean $L H F$ using $A N N, R F, \mathrm{BR}$ and $R A N S A C$ (unit $\mathrm{W} \mathrm{m}^{-2}$ ). 
All of the ocean LHF products yielded lower LHF estimates over the equatorial region, especially over the East Pacific along South America and the East Atlantic along Africa. The highest ocean LHF exceeded approximately $200 \mathrm{~W} \mathrm{~m}^{-2}$ and occurred in the South Pacific with latitudes between $10^{\circ}$ and $20^{\circ} \mathrm{S}$. Even though ocean $L H F$ products have similar spatial distribution in low-latitude areas, there are still significant differences between different products. As shown in Figure 9, MERRA-2 and GSSTF-3 products yielded higher LHF values in the South Pacific and South Indian Ocean. Compared with MERRA-2, JOFURO-3, ERA-I and GSSTF-3, OAFlux yielded lower ocean LHF values over low-latitude areas. In contrast, the spatial distribution of $A N N, B R$ and $R A N S A C$ showed highly consistent characteristics. However, it is also noted that the ocean LHF estimation from RF cannot properly simulate the high ocean LHF values, which may be because the RF algorithm highly depends on the representativeness of the sample dataset; if the sample dataset does not include the high ocean $L H F$ value, it may cause a deviation in LHF results. The ocean LHF of four ensemble products is much lower than that from the four individual ocean products, but close to that from the reference dataset (OAFlux product).

Figure 10 shows the comparison of the annual average $L H F$ from $A N N$ versus that of the other three methods ( $R F, B R$ and $R A N S A C$ ) over low-latitude areas. In general, the ocean $L H F$ from $A N N$ agrees best with $B R$, followed by RANSAC. The most prominent difference between $A N N$ and $B R$ is that the $L H F$ values estimated by $A N N$ were lower than those of $B R$ when $L H F$ was greater than $150 \mathrm{~W} \mathrm{~m}^{-2}$ and higher than those of $B R$ when it was less than $50 \mathrm{~W} \mathrm{~m}^{-2}$. When the ocean $L H F$ was lower than $10 \mathrm{~W} \mathrm{~m}^{-2}$, RANSAC poorly simulated $L H F$ variability. The estimated LHF from $A N N$ was higher than those of $R F$ when ocean $L H F$ was greater than $130 \mathrm{~W} \mathrm{~m}^{-2}$ and lower than those of $R F$ when it was less than $20 \mathrm{~W} \mathrm{~m}^{-2}$. The discrepancies may be mainly caused by the difference in algorithm structure. As shown in Figure 9, the estimated ocean LHF from ANN was close to that from the other three $M L$ methods, indicated by an $R^{2}$ higher than 0.98 and bias less than $3.5 \mathrm{~W} \mathrm{~m}^{-2}$. As mentioned above, the estimated LHF from $B R$ was closest to that of $A N N$, as characterized by the highest $R^{2}$, the lowest RMSE and lowest bias.
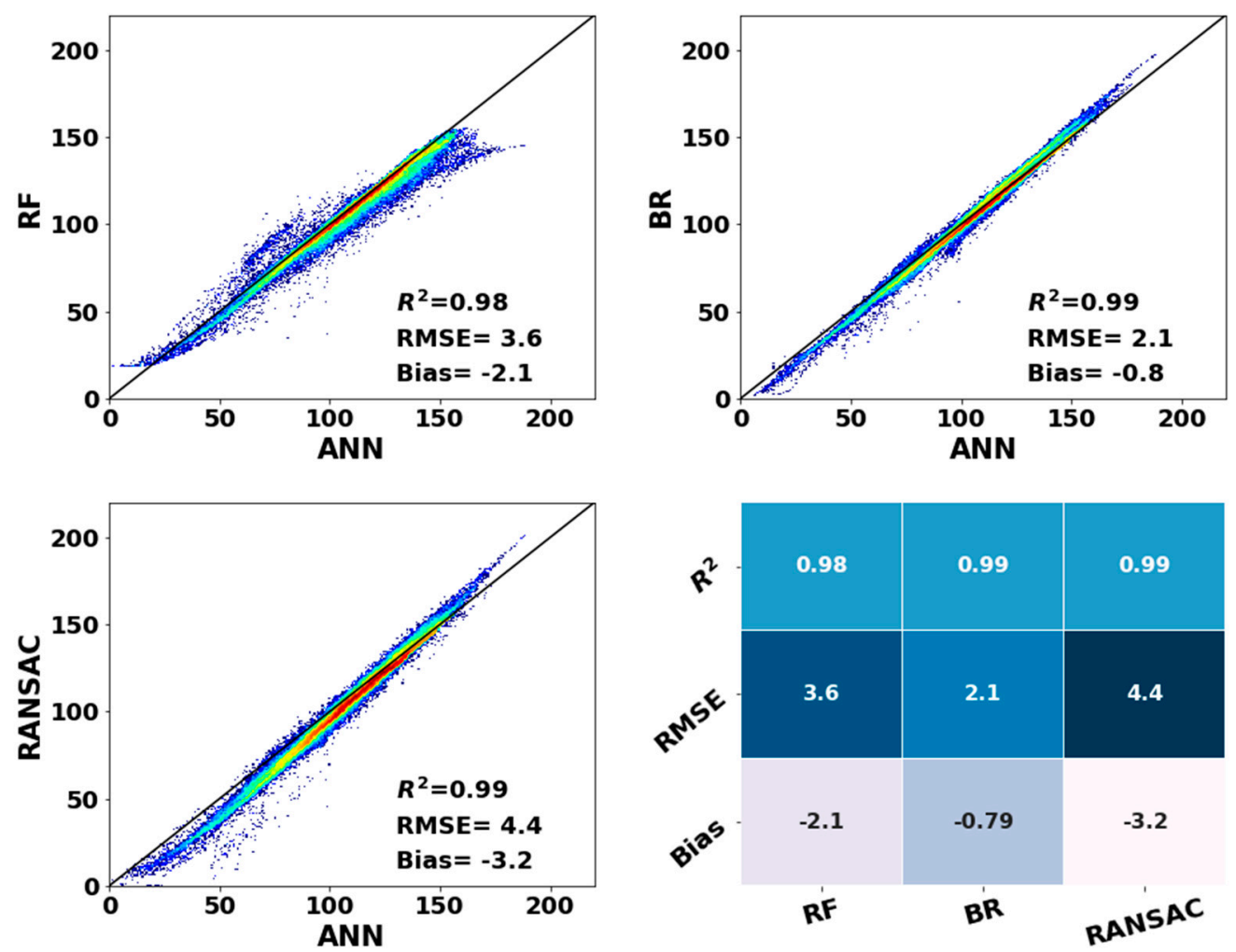

Figure 10. Comparison of monthly ocean $L H F$ from $A N N$ and other $M L$ methods (unit $\mathrm{W} \mathrm{m}^{-2}$ ). 
Figure 11 shows spatial differences in annual ocean $L H F$ over low-latitude regions between $A N N$ and the other three ML methods (RF,BR and RANSAC). The differences in annual ocean LHF estimated by $A N N$ and the other three $M L$ methods were mainly distributed in the range of -10 to $10 \mathrm{~W} \mathrm{~m}^{-2}$. The ensemble ocean $L H F$ product from $B R$ also showed a consistent spatial distribution with that of $A N N$; the difference was less than $5 \mathrm{~W} \mathrm{~m}^{-2}$ in most areas. The ensemble LHF using RANSAC has the most significant variation in spatial distribution. RANSAC yields high ocean LHF mainly in the Equatorial East Pacific and Equatorial East Atlantic; this may be caused by the differences in different $M L$ methods.
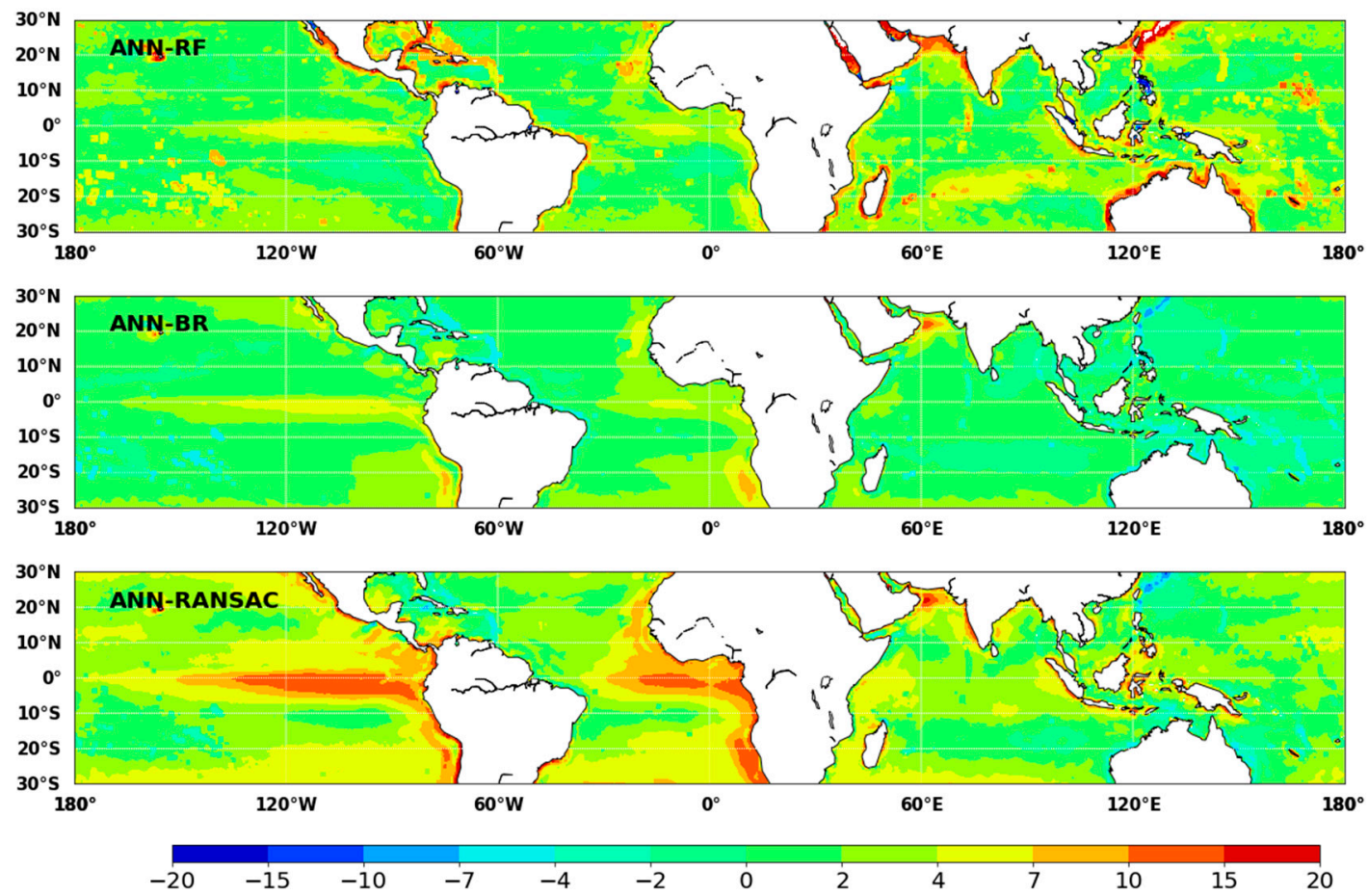

Figure 11. Maps of spatial difference in annual average ocean $L H F$ between $A N N$ and other $M L$ methods (RF, BR and RANSAC) over low-latitude area during 2003-2007 (unit $\mathrm{W} \mathrm{m}^{-2}$ ).

\subsubsection{Seasonal Patterns of the Ensemble Tropical Ocean LHF}

Figure 12 presents the multiyear average seasonal pattern of ocean $L H F$, which shows that strong regional variations occur in low-latitude areas. The variation in ocean $L H F$ is affected by the climate and land-sea distribution. Lower wind speeds and lower sea temperatures due to proximity to land result in the lowest ocean LHF in the equatorial current region of the eastern Pacific. Moreover, the maximum ocean LHF occurs in the central Pacific.

In the northern hemisphere, ocean $L H F$ increased from fall then decreased from spring to fall over tropical areas. The lowest ocean $L H F$ in the southern hemisphere occurs in spring; there was a sharp increase in ocean LHF from spring to fall. In the winter of the northern hemisphere, the largest ocean LHF occurs in the Kuroshio Current, followed by the Gulf Stream; the average ocean LHF exceeds $200 \mathrm{~W} \mathrm{~m}^{-2}$ in these regions. Ocean LHF values are large in the Kuroshio Current and Gulf Stream due to the large temperature differences at the air-sea interface. Similarly, the largest ocean LHF of the southern hemisphere occurs in the South Pacific, especially in the $10^{\circ}$ and $20^{\circ}$ south latitude.

Compared to the RF method, the $A N N$ method exhibited a good ability to simulate spatial variability. $R F$ performed poorly in simulating high ocean $L H F$ in ocean current regions, such as the Kuroshio Current area in the northern hemisphere's winter, and Australia's bordering sea. This may be caused by the fact that $R F$ has a different algorithm structure compared to those of the other $M L$ methods. According to the ANN method, fall has the highest average ocean LHF $\left(113.8 \mathrm{~W} \mathrm{~m}^{-2}\right)$, followed by summer $\left(113.0 \mathrm{~W} \mathrm{~m}^{-2}\right)$, spring $\left(112.7 \mathrm{~W} \mathrm{~m}^{-2}\right)$ and winter $\left(111.2 \mathrm{~W} \mathrm{~m}^{-2}\right)$. 


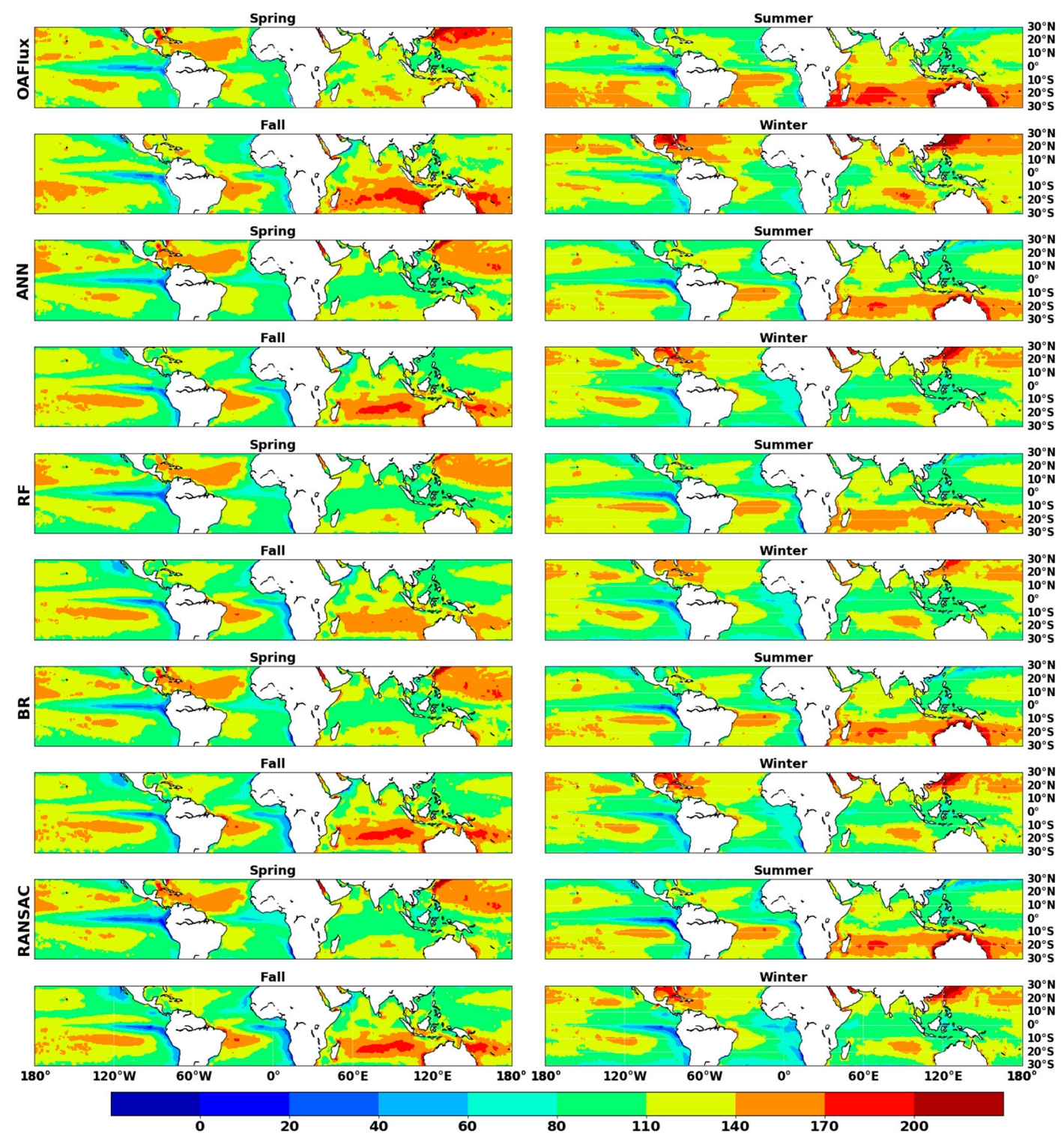

Figure 12. Maps of multiyear (2003-2007) average seasonality of ocean LHF estimations from OAFlux product and four $M L$ methods (unit $\mathrm{W} \mathrm{m}^{-2}$ ).

Figure 13 illustrates the latitudinal variation in annual average $L H F$ over low-latitude areas during 2003-2007. Despite the general differences in latitude distribution among different ocean LHF estimates, the latitudinal distribution of all ocean LHF estimations is bimodal, and the highest ocean LHF occurs at approximately $15^{\circ} \mathrm{S}$, followed by $15^{\circ} \mathrm{N}$. The minimum values appear in the equatorial region, and the LHF gradually increases with the increase in latitude. After reaching the maximum value at approximately $15^{\circ}$, ocean $L H F$ gradually declines to the poles. There are still substantial differences between the seven ocean $L H F$ estimates. Compared to reanalysis datasets that overestimate ocean LHF against buoy site observation, ANN is closer to OAFlux and JOFURO-3. Moreover, ANN-based ensemble $L H F$ can capture more detailed information than OAFlux owing to its high spatial resolution. Although the estimated ocean LHF of four ML methods are very close, the estimated LHF using ANN is slightly higher than others by $3-5 \mathrm{~W} \mathrm{~m}^{-2}$.

Figure 14 compares the monthly average ocean $L H F$ derived from $A N N$ and the other $M L$ methods with other ocean $L H F$ products over the tropics. All the ocean $L H F$ estimates presented similar seasonal variability, and the magnitude of ocean $L H F$ seasonal variation was less than $10 \mathrm{~W} \mathrm{~m}^{-2}$. Ocean $L H F$ increased from April to June then decreased from June to October due to the high ocean LHF in the 
southern hemisphere. Figure 13 also illustrates that the reanalysis product (ERA-I) was $10-30 \mathrm{~W} \mathrm{~m}^{-2}$ higher than others. The $L H F$ derived from the four $M L$ methods was closer and more than $10 \mathrm{~W} \mathrm{~m}^{-2}$ lower than those derived from the other products. Among them, $A N N$ is slightly higher than other $M L$ methods by $1-3 \mathrm{~W} \mathrm{~m}^{-2}$.

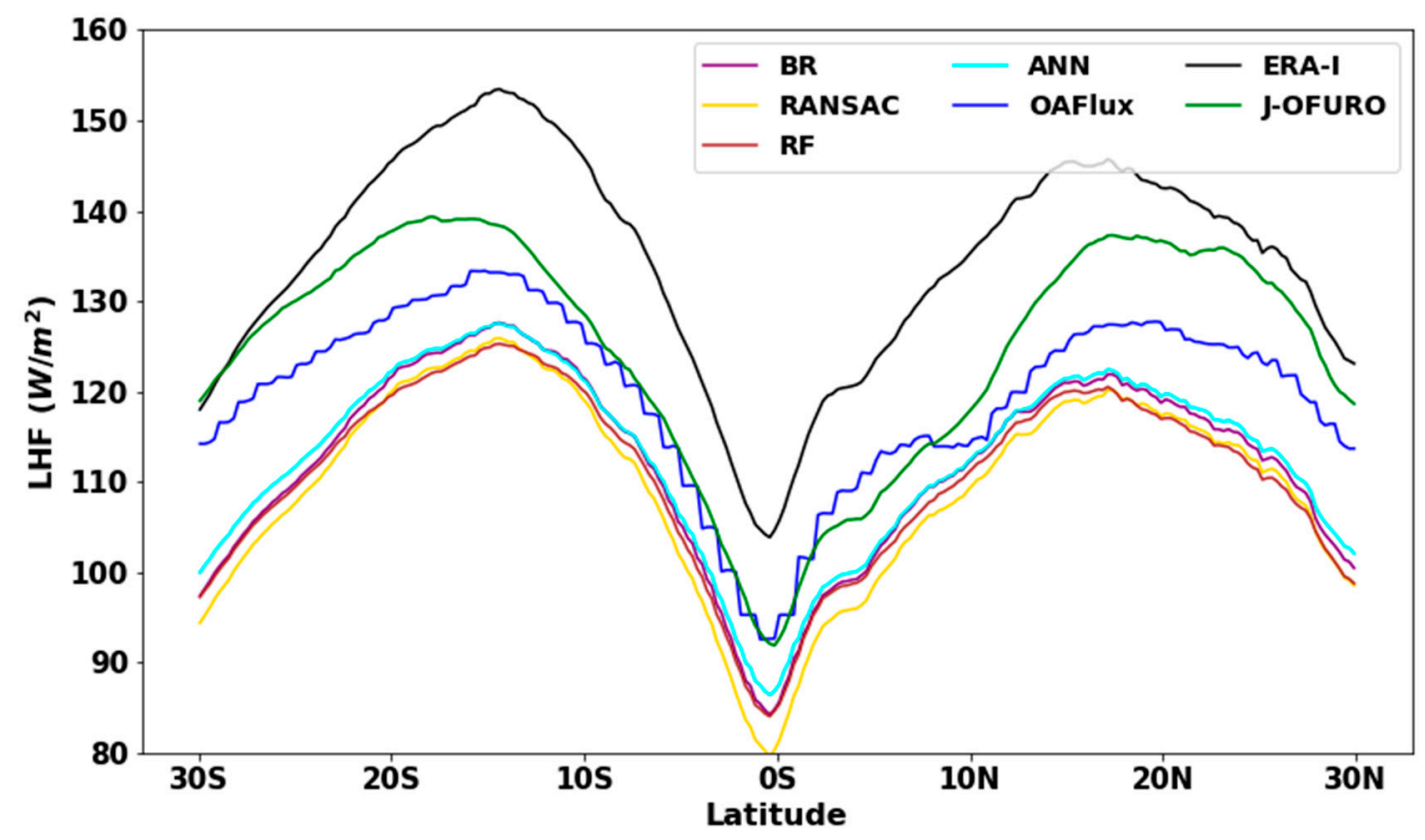

Figure 13. Latitudinal variation of annual average LHF over low-latitude area during 2003-2007, (unit $\mathrm{W} \mathrm{m}^{-2}$ ).

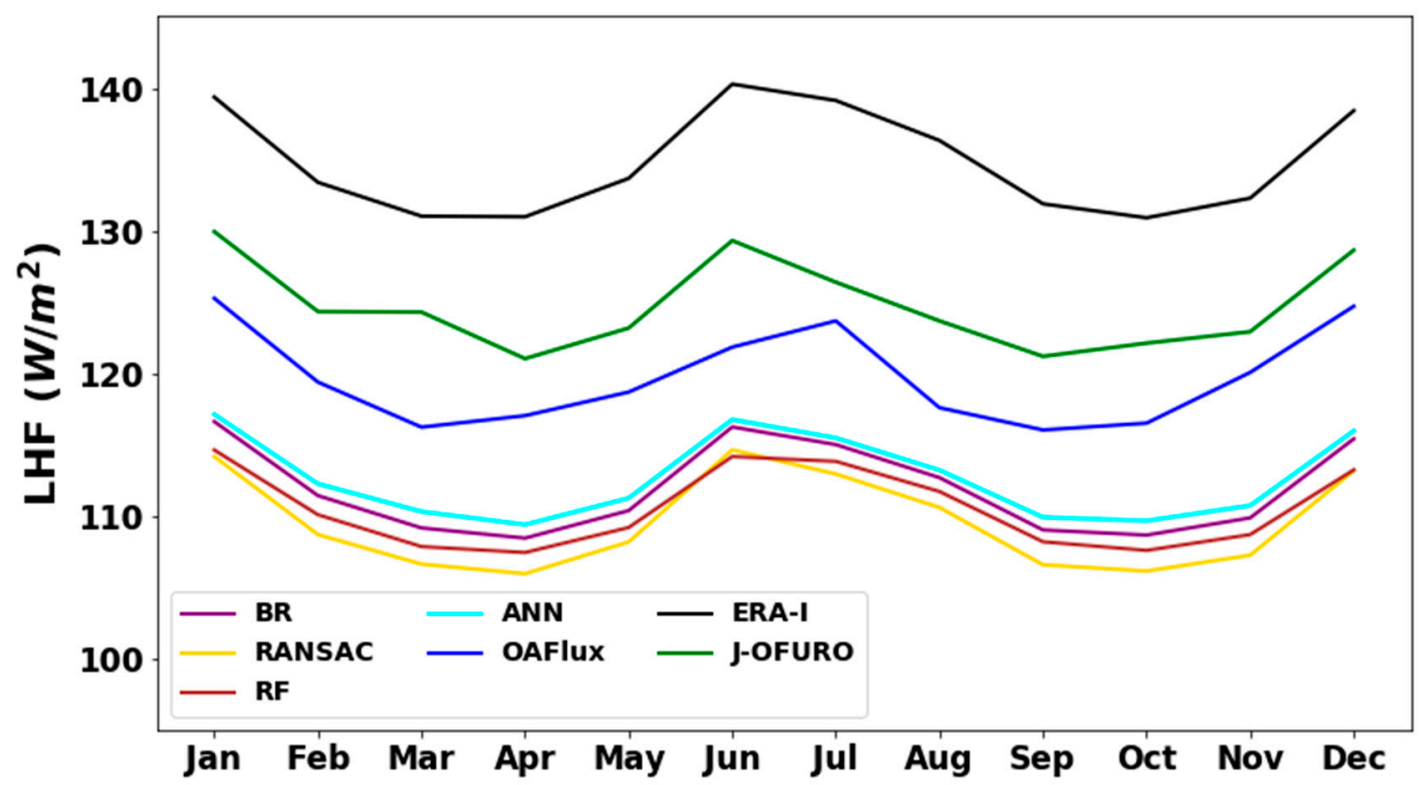

Figure 14. Annual variation of annual average $L H F$ over low-latitude regions during the period of 2003 to 2007 (unit $\mathrm{W} \mathrm{m}^{-2}$ ).

\section{Discussion}

$A N N, R F, B R$ and $R A N S A C$ were used to estimate ocean $L H F$ at a spatial resolution of $0.25^{\circ}$. Some of these four $M L$ methods were successfully used to estimate a terrestrial LE fusion product, such as ANN and $R F[49,67,68]$. According to validation against buoy observations (Figure 4), our results illustrate that ensemble ocean $L H F$ from $M L$ methods performed much better than the estimated $L H F$ from 
four individual ocean LHF products (MERRA-2, JOFURO-3, ERA-I and GSSTF-3). Compared to the individual $L H F$ products, the $R^{2}$ of the $M L$ methods was $3.7-46.4 \%$ higher and the bias decreased by approximately $15 \mathrm{~W} \mathrm{~m}^{-2}$. Our results also show that some minor differences existed among the four $M L$ methods, which are mainly affected by the structure of different fusion algorithms $[69,70]$. Sagi and Rokach [71] showed that the differences in structure of the ensemble methods may significantly affect the predictions, and the best ensemble method for a given problem needs to consider other factors (such as suitability to a given setting).

The ensemble ocean $L H F$ from ANN showed great consistency with that of the other three $M L$ methods. The difference in the spatiotemporal variation of ensemble $L H F$ from the four $M L$ methods was less than $5 \mathrm{~W} \mathrm{~m}^{-2}$ and were all $10-30 \mathrm{~W} \mathrm{~m}^{-2}$ lower than the individual ocean $L H F$ products. In comparison with the $R F, B R$ and $R A N S A C$ methods, the ocean $L H F$ estimation using $A N N$ performed better. This may be attributed to the fact that $A N N$ is composed of a series of adaptively connected simple neuron nodes, which improves the accuracy of model estimation by adjusting the weights between different neurons [59,72]. Other studies also found that $A N N$ presents a superior ensemble performance to other $M L$ methods in many fields, such as $E T$, solar radiation and downscaling $[67,73,74]$.

Similar to $A N N, R F$ has a strong correlation with observations (Figure 4), but we found that ocean $L H F$ estimations from $R F$ performed poorly in simulating high $L H F$ values in the spatiotemporal distribution. This is consistent with the conclusions drawn by Zhang et al. [75]; the regression prediction obtained by RF performs poorly, while $A N N$ achieves the best estimation of the total biomass in four $M L$ methods. This may be due to the fact that the training of $R F$ not only requires a large amount of sample dataset [76] but also requires the sample dataset itself to be representative. Studies have shown that increasing the number and periodicity of sample datasets can improve the estimation accuracy of $R F$ [77]. Considering that the buoy site observations cannot cover all the ocean LHF features in the study area, the $R F$ method underperformed the other three $M L$ methods in simulating the spatial and temporal distribution of $L H F$.

We also applied the TCH method to evaluate relative uncertainties among the four ocean LHF fusion products and four individual LHF products because the TCH method has been successfully used in territorial $L E$ uncertainty evaluation [78-80]. All $M L$ methods performed better than individual ocean $L H F$ products as indicated by lower relative uncertainty. The relative uncertainty of the four ensemble products was approximately $5 \mathrm{~W} \mathrm{~m}^{-2}$, while relative uncertainty of the individual ocean $L H F$ products ranged from 7 to $20 \mathrm{~W} \mathrm{~m}^{-2}$. ANN had the lowest average uncertainty, followed by $B R$. The average relative uncertainty of $R F$ was the highest among the four $M L$ methods.

In terms of the spatial distribution of relative uncertainty, the high relative uncertainty values of $R F$ were mainly located in the extreme values of ocean LHF (Figures 7 and 12). The uncertainties of the ensemble LHF products mainly stemmed from the biases of the individual datasets [21], the errors in the buoy site observations [81], the mismatched spatial scales between datasets from different sources and the structure of $M L$ methods $[71,82,83]$. Due to the measurement sensors and environmental disturbances, the uncertainties in ocean $L H F$ observations obtained from buoy sites array were approximately $10 \mathrm{~W} \mathrm{~m}^{-2}[44,56,81]$. The representativeness of the buoy site ranges from tens to hundreds of meters, while the spatial resolution of LHF products was greater than $12.5 \mathrm{~km}$, the spatial resolution mismatch may lead to uncertainties in the validation results. Additionally, the errors in the individual products will lead to an $8 \%$ error in ensemble LHF [21,84]. The mismatches among different data sources may also introduce a 5-7\% uncertainty in ensemble LHF [85-87]. Although the $M L$ methods do not require a priori knowledge, the structure of different $M L$ methods may lead to large errors and poor generalization performance [84].

Our study provided future efforts to improve ocean $L H F$ estimation using $M L$ methods by an ensemble of multiple $L H F$ products. $M L$ methods performed better in estimating ocean $L H F$ than the individual ocean LHF products (MERRA-2, JOFURO-3, ERA-I and GSSTF-3). All these products can be well trained by observations and then used for estimating ocean $L H F$. Importantly, different $M L$ methods need to be fully evaluated in different studies. For example, $R F$ has higher relative uncertainty 
at the region of extreme $L H F$ values, but that is not conclusive. In contrast, $A N N$ presents lower relative uncertainty in global or regional ocean $L H F$ estimations. Therefore, ANN can be considered an ideal method to replace $R F$ when generating tropical ocean $L H F$ products.

\section{Conclusions}

We applied $A N N$ and three other $M L$ methods (RF, BR and $R A N S A C)$ to improve tropical ocean LHF estimation by ensemble of satellite and reanalysis products (MERRA-2, JOFURO-3, ERA-I and GSSTF-3) and evaluate the performance of fusion products based on reference product (OAFlux) and buoy observations. The $M L$ models used here were trained (tested) using observations from 81 (34) buoy sites over low-latitude areas from 2003 to 2007.

By merging individual LHF product, our results show that the ensemble LHF products derived from four $M L$ methods were significantly superior to the individual $L H F$ products with higher accuracy and lower bias. Among them, ANN performs best, indicated by the highest $R^{2}(0.88$ and 0.87$)$, the lowest RMSE (10.4 and 10.9) and the highest KGE (0.89 and 0.90) for training and testing, respectively.

By quantifying relative uncertainties by the TCH method, we found that the relative uncertainties of ensemble LHF products were also significantly lower than individual LHF product, which lead to the conclusion that the individual product's uncertainties caused by errors in algorithm and input datasets can be reduced by merging multiple products. In addition, $A N N$ generated lower relative uncertainty than the other three $M L$ methods. The result demonstrates that $A N N$ can be considered an ideal method to replace $R F$ when generating tropical ocean $L H F$ products.

Author Contributions: X.C. and Y.Y. designed the work and prepared the manuscript. Y.L. and Y.Z. corrected and improved the manuscript. K.J. and X.Z. conducted the remotely sensed image processing. K.S., X.B., J.Y. and X.G. contributed by providing additional analysis to the discussion. All authors have read and agreed to the published version of the manuscript.

Funding: This work was partially supported by the National Key Research Development Program of China (No.2016YFA0600103 and No.2016YFA0600102) and the Natural Science Fund of China (No.41671331 and No. 41701483).

Acknowledgments: We thank Shaomin Liu, Tongren $\mathrm{Xu}$, Zhongli Zhu and Linna Chai from the Faculty of Geographical Science, Beijing Normal University, China, and Xin Wang and Rongwang Zhang from the State Key Laboratory of Tropical Oceanography, South China Sea Institute of Oceanology, Chinese Academy of Sciences, China, for their suggestions to improve this manuscript. We also thank the International Science Editing group (http://www.internationalscienceediting.com) for editing this manuscript. All of the data used are listed in the references. Buoy sites observations (TAO, PIRATA and RAMA) were obtained from Pacific Marine Environmental Laboratory (PMEL) of National Oceanic and Atmospheric Administration (https://www.pmel.noaa.gov/gtmba/). MERRA-2 and GSSTF-3 were obtained from the Earth data website (https://earthdata.nasa.gov/). ERA-I was obtained from public dataset of ECMWF website (https://www.ecmwf.int/). AMSR-E, JRA-25, J-OFURO, NCEP-2 and OAFlux were obtained from the ASIA-PACIFIC DATA-RESEARCH CENTER (APDRC) (http://apdrc.soest. hawaii.edu/index.php).

Conflicts of Interest: The authors declare no conflict of interest.

\section{References}

1. Fairall, C.W.; Bradley, E.F.; Rogers, D.P.; Edson, J.B.; Young, G.S. Bulk parameterization of air-sea fluxes for Tropical Ocean-Global Atmosphere Coupled-Ocean Atmosphere Response Experiment. J. Geophys. Res. Oceans 1996, 101, 3747-3764. [CrossRef]

2. Cayan, D.R. Latent and Sensible Heat Flux Anomalies over the Northern Oceans: Driving the Sea Surface Temperature. J. Phys. Oceanogr. 1992, 22, 859-881. [CrossRef]

3. Lee, H.-K.; Chu, P.-S.; Sui, C.H.; Lau, K.-M. On the Annual Cycle of Latent Heat Fluxes over the Equatorial Pacific Using TAO Buoy Observations. J. Meteorol. Soc. Jpn. 1998, 76, 909-923. [CrossRef]

4. Chen, S.; Li, W.; Lu, Y.; Wen, Z. Variations of latent heat flux during tropical cyclones over the South China Sea. Meteorol. Appl. 2013, 21,717-723. [CrossRef]

5. Schulz, J.; Meywerk, J.; Ewald, S.; Schlüssel, P. Evaluation of Satellite-Derived Latent Heat Fluxes. J. Clim. 1997, 10, 2782-2795. [CrossRef] 
6. Yu, L.; Weller, R.A. Objectively analyzed air-sea heat fluxes for the global ice-free oceans (1981-2005). Bull. Am. Meteorol. Soc. 2007, 88, 527-540. [CrossRef]

7. Zeng, L.; Shi, P.; Liu, W.T.; Wang, D. Evaluation of a satellite-derived latent heat flux product in the South China Sea: A comparison with moored buoy data and various products. Atmos. Res. 2009, 94, 91-105. [CrossRef]

8. Qu, S. Observation research of the turbulent fluxes of momentum, sensible heat and latent heat over the west pacific tropical ocean orea. Adv. Atmos. Sci. 1989, 6, 254. [CrossRef]

9. Gong, Y.; Sun, J.; Shi, X.; Xu, J.; Yu, B.; Yu, H. Long-Term Trend Analysis of Latent Heat in Tropical Oceans. Period. Ocean Univ. China 2013, 43, 15-23.

10. Jiang, H.; Wang, H.; Wu, D. Seasonal variability of turbulent heat fluxes in the tropical Atlantic Ocean based on WHOI flux product. Acta Oceanol. Sin. 2007, 26, 1-11.

11. Yao, Y.; Liang, S.; Li, X.; Chen, J.; Wang, K.; Jia, K.; Cheng, J.; Jiang, B.; Fisher, J.B.; Mu, Q.; et al. A satellite-based hybrid algorithm to determine the Priestley-Taylor parameter for global terrestrial latent heat flux estimation across multiple biomes. Remote Sens. Environ. 2015, 165, 216-233. [CrossRef]

12. Brocks, K.; Augstein, E.; Krugerme, L. Turbulent Vertical Fluxes in Planetary Boundary Layer and Their Relation to Synoptic-Scale Processes during Atlantic-Trade-Wind-Experiment 1969 (Atex). Bull. Am. Meteorol. Soc. 1970, $51,287$.

13. Fleagle, R.G. Bomex-Appraisal of Results. Science 1972, 176, 1079-1084. [CrossRef] [PubMed]

14. Pollard, R.T. The Joint Air-Sea Interaction Experiment-JASIN 1978. Bull. Am. Meteorol. Soc. 1978, 59, $1310-1318$. [CrossRef]

15. Lukas, R.; Webster, P.J. Toga-Coare-Tropical Ocean Global Atmosphere Program and Coupled Ocean-Atmosphere Response Experiment. Oceanus 1992, 35, 62-65.

16. Kondratev, K.Y. Global Energy and Water Cycle Experiment (Gewex)-The Role of Space Observation Facilities. Sov. J. Remote Sens. 1993, 10, 951-964.

17. Giese, M. Joint Global Ocean Flux Study (JGOFS). Environ. Sci. Pollut. Res. 1994, 1, 177. [CrossRef]

18. Tomita, H.; Hihara, T.; Kako, S.; Kubota, M.; Kutsuwada, K. An introduction to J-OFURO3, a third-generation Japanese ocean flux data set using remote-sensing observations. J. Oceanogr. 2018, 75, 171-194. [CrossRef]

19. Shie, C.L. Science Background for the Reprocessing and Goddard Satellite-Based Surface Turbulent Fluxes (GSSTF3) Dataset for Global Water and Energy Cycle Research; Research Gate: Berlin, Germany, 2012.

20. Jost, V.; Bakan, S.; Fennig, K. HOAPS-A new satellite-derived freshwater flux climatology. Meteorol. Z. 2002, 11, 61-70. [CrossRef]

21. Brunke, M.; Wang, Z.; Zeng, X.; Bosilovich, M.; Shie, C.-L. An Assessment of the Uncertainties in Ocean Surface Turbulent Fluxes in 11 Reanalysis, Satellite-Derived, and Combined Global Datasets. J. Clim. 2011, 24, 5469-5493. [CrossRef]

22. Bentamy, A.; Piollé, J.-F.; Grouazel, A.; Danielson, R.E.; Gulev, S.; Paul, F.; Azelmat, H.; Mathieu, P.; Von Schuckmann, K.; Sathyendranath, S.; et al. Review and assessment of latent and sensible heat flux accuracy over the global oceans. Remote Sens. Environ. 2017, 201, 196-218. [CrossRef]

23. Chou, S.-H. A comparison of airborne eddy correlation and bulk aerodynamic methods for ocean-air turbulent fluxes during cold-air outbreaks. Bound. Layer Meteorol. 1993, 64, 75-100. [CrossRef]

24. Janssen, J.A.M. Does Wind Stress Depend on Sea-State or Not?-A Statistical Error Analysis of Hexmax Data. Bound. Layer Meteorol. 1997, 83, 479-503. [CrossRef]

25. Pedreros, R.; Dardier, G.; Dupuis, H.; Graber, H.C.; Drennan, W.M.; Nacass, P.; Weill, A.; Guerin, C. Momentum and heat fluxes via the eddy correlation method on the R/VL'Atalanteand an ASIS buoy. J. Geophys. Res. Space Phys. 2003, 108, 11. [CrossRef]

26. Hodur, R.M. The Naval Research Laboratory's Coupled Ocean/Atmosphere Mesoscale Prediction System (COAMPS). Mon. Weather Rev. 1997, 125, 1414-1430. [CrossRef]

27. Kanamitsu, M.; Kumar, A.; Juang, H.-M.H.; Schemm, J.-K.; Wang, W.; Yang, F.; Hong, S.-Y.; Peng, P.; Chen, W.; Moorthi, S.; et al. NCEP Dynamical Seasonal Forecast System 2000. Bull. Am. Meteorol. Soc. 2002, 83, 1019-1037. [CrossRef]

28. Miller, R.N.; Carter, E.F.; Blue, S.T. Data assimilation into nonlinear stochastic models. Tellus A Dyn. Meteorol. Oceanogr. 1999, 51, 167-194. [CrossRef]

29. Roquet, H.; Planton, S.; Gaspar, P. Determination of ocean surface heat fluxes by a variational method. J. Geophys. Res. Space Phys. 1993, 98, 10211. [CrossRef] 
30. Skachko, S.; Brankart, J.-M.; Castruccio, F.; Brasseur, P.; Verron, J. Improved Turbulent Air-Sea Flux Bulk Parameters for Controlling the Response of the Ocean Mixed Layer: A Sequential Data Assimilation Approach. J. Atmos. Ocean. Technol. 2009, 26, 538-555. [CrossRef]

31. Depuis, G. Influence of Nitrogen-Fertilizer and Row Spacing of Companion Crop Harvested at Forage on the Establishment of Alfalfa. Can. J. Plant. Sci. 1983, 63, 443-452. [CrossRef]

32. Bourassa, M.A.; Vincent, D.G.; Wood, W.L. A Flux Parameterization Including the Effects of Capillary Waves and Sea State. J. Atmos. Sci. 1999, 56, 1123-1139. [CrossRef]

33. Large, W.G.; Pond, S. Open Ocean Momentum Flux Measurements in Moderate to Strong Winds. J. Phys. Oceanogr. 1981, 11, 324-336. [CrossRef]

34. Large, W.G.; Pond, S. Sensible and Latent-Heat Flux Measurements over the Ocean. J. Phys. Oceanogr. 1982, 12, 464-482. [CrossRef]

35. Anderson, R.J. A Study of Wind Stress and Heat Flux over the Open Ocean by the Inertial-Dissipation Method. J. Phys. Oceanogr. 1993, 23, 2153-2161. [CrossRef]

36. Fairall, C.W.; Larsen, S.E. Inertial-Dissipation methods and turbulent fluxes at the air-ocean interface. Bound. Layer Meteorol. 1986, 34, 287-301. [CrossRef]

37. Huntley, D.A. A Modified Inertial Dissipation Method for Estimating Seabed Stresses at Low Reynolds Numbers, with Application to Wave/Current Boundary Layer Measurements. J. Phys. Oceanogr. 1988, 18, 339-346. [CrossRef]

38. Yelland, M.J.; Taylor, P.K.; Consterdine, I.E.; Smith, M.H. The Use of the Inertial Dissipation Technique for Shipboard Wind Stress Determination. J. Atmos. Ocean. Technol. 1994, 11, 1093-1108. [CrossRef]

39. Jones, R.W.; Renfrew, I.A.; Orr, A.; Webber, B.G.M.; Holland, D.M.; Lazzara, M.A. Evaluation of four global reanalysis products using in situ observations in the Amundsen Sea Embayment, Antarctica. J. Geophys. Res. Atmos. 2016, 121, 6240-6257. [CrossRef]

40. Lindsay, R.; Wensnahan, M.; Schweiger, A.; Zhang, J. Evaluation of Seven Different Atmospheric Reanalysis Products in the Arctic. J. Clim. 2014, 27, 2588-2606. [CrossRef]

41. Su, T.; Feng, G. Spatial-Temporal variation characteristics of global evaporation revealed by eight reanalyses. Sci. China Earth Sci. 2014, 58, 255-269. [CrossRef]

42. Liu, W.T.; Katsaros, K.B.; Businger, J.A. Comments on Bulk Parameterization of Air-Sea Exchanges of Heat and Water-Vapor Including the Molecular Constraints at the Interface-Reply. J. Atmos. Sci. 1980, 37, 2801-2802. [CrossRef]

43. Brunke, M.A.; Fairall, C.W.; Zeng, X.B.; Eymard, L.; Curry, J.A. Which bulk aerodynamic algorithms are least problematic in computing ocean surface turbulent fluxes? J. Clim. 2003, 16, 619-635. [CrossRef]

44. Jiang, C.; Cronin, M.F.; Kelly, K.A.; Thompson, L. Evaluation of a hybrid satellite- and NWP-based turbulent heat flux product using Tropical Atmosphere-Ocean (TAO) buoys. J. Geophys. Res. Space Phys. 2005, 110, 9. [CrossRef]

45. Bourras, D. Comparison of Five Satellite-Derived Latent Heat Flux Products to Moored Buoy Data. J. Clim. 2006, 19, 6291-6313. [CrossRef]

46. Wang, D.; Wang, D.; Li, X.; Shi, P. Validation of Satellite-Derived Daily Latent Heat Flux over the South China Sea, Compared with Observations and Five Products. J. Atmos. Ocean. Technol. 2013, 30, 1820-1832. [CrossRef]

47. Yao, Y.; Liang, S.; Li, X.; Chen, J.; Liu, S.; Jia, K.; Zhang, X.; Xiao, Z.; Fisher, J.; Mu, Q.; et al. Improving global terrestrial evapotranspiration estimation using support vector machine by integrating three process-based algorithms. Agric. For. Meteorol. 2017, 242, 55-74. [CrossRef]

48. Fan, J.; Yue, W.; Wu, L.; Zhang, F.; Cai, H.; Wang, X.; Lu, X.; Xiang, Y. Evaluation of SVM, ELM and four tree-based ensemble models for predicting daily reference evapotranspiration using limited meteorological data in different climates of China. Agric. For. Meteorol. 2018, 263, 225-241. [CrossRef]

49. Shang, K.; Yao, Y.; Li, Y.; Yang, J.; Jia, K.; Zhang, X.; Chen, X.; Bei, X.; Guo, X. Fusion of Five Satellite-Derived Products Using Extremely Randomized Trees to Estimate Terrestrial Latent Heat Flux over Europe. Remote Sens. 2020, 12, 687. [CrossRef]

50. Rienecker, M.M.; Suarez, M.J.; Gelaro, R.; Todling, R.; Bacmeister, J.; Liu, E.; Bosilovich, M.G.; Schubert, S.D.; Takacs, L.; Kim, G.K.; et al. MERRA: NASA's Modern-Era Retrospective Analysis for Research and Applications. J. Clim. 2011, 24, 3624-3648. [CrossRef] 
51. Schade, N.H.; Heinrich, H.; Rosenhagen, G. Regional Evaluation of ERA-40 Reanalysis Data with Marine Atmospheric Observations in the North Sea Area. Meteorol. Z 2013, 22, 675-684. [CrossRef]

52. Molod, A.; Takács, L.; Suárez, M.; Bacmeister, J. Development of the GEOS-5 atmospheric general circulation model: Evolution from MERRA to MERRA2. Geosci. Model Dev. 2015, 8, 1339-1356. [CrossRef]

53. Simmons, S.E.; Cobb, C.R. Stone tool traditions in the contact era. Am. Antiq. 2006, 71, 788-789. [CrossRef]

54. Yu, L.; Weller, R.A.; Sun, B. Mean and Variability of the WHOI Daily Latent and Sensible Heat Fluxes at In Situ Flux Measurement Sites in the Atlantic Ocean. J. Clim. 2004, 17, 2096-2118. [CrossRef]

55. Servain, J.; Busalacchi, A.J.; McPhaden, M.; Moura, A.D.; Reverdin, G.; Vianna, M.L.; Zebiak, S.E. A Pilot Research Moored Array in the Tropical Atlantic (PIRATA). Bull. Am. Meteorol. Soc. 1998, 79, 2019-2031. [CrossRef]

56. McPhaden, M.J.; Meyers, G.; Ando, K.; Masumoto, Y.; Murty, V.S.N.; Ravichandran, M.; Syamsudin, F.; Vialard, J.; Yu, L.; Yu, W. Supplement to RAMA: The Research Moored Array for African-Asian-Australian Monsoon Analysis and Prediction. Bull. Am. Meteorol. Soc. 2009, 90, ES5-ES8. [CrossRef]

57. Hayes, S.P.; Mangum, L.J.; Picaut, J.; Sumi, A.; Takeuchi, K. TOGA-TAO: A Moored Array for Real-time Measurements in the Tropical Pacific Ocean. Bull. Am. Meteorol. Soc. 1991, 72, 339-347. [CrossRef]

58. McPhaden, M.J. The Tropical Atmosphere Ocean Array Is Completed. Bull. Am. Meteorol. Soc. 1995, 76, 739-744. [CrossRef]

59. Khashei, M.; Bijari, M. An artificial neural network (p,d,q) model for timeseries forecasting. Expert Syst. Appl. 2010, 37, 479-489. [CrossRef]

60. Hsiang, T.C. A Bayesian View on Ridge Regression. J. R. Stat. Soc. Ser. D Stat. 1975, 24, 267. [CrossRef]

61. Fischler, M.; Bolles, R. Random sample consensus: A paradigm for model fitting with applications to image analysis and automated cartography. Commun. ACM 1981, 24, 381-395. [CrossRef]

62. Tavella, P.; Premoli, A. Estimating the Instabilities ofNClocks by Measuring Differences of their Readings. Metrologia 1994, 30, 479-486. [CrossRef]

63. Ferreira, V.G.; Montecino, H.D.; Yakubu, C.I.; Heck, B. Uncertainties of the Gravity Recovery and Climate Experiment time-variable gravity-field solutions based on three-cornered hat method. J. Appl. Remote Sens. 2016, 10, 15015. [CrossRef]

64. Khan, M.S.; Liaqat, U.W.; Baik, J.; Choi, M. Stand-Alone uncertainty characterization of GLEAM, GLDAS and MOD16 evapotranspiration products using an extended triple collocation approach. Agric. For. Meteorol. 2018, 252, 256-268. [CrossRef]

65. Crow, W.T.; Su, C.-H.; Ryu, D.; Yilmaz, M.T. Optimal averaging of soil moisture predictions from ensemble land surface model simulations. Water Resour. Res. 2015, 51, 9273-9289. [CrossRef]

66. Premoli, A.; Tavella, P. A revisited three-cornered hat method for estimating frequency standard instability. IEEE Trans. Instrum. Meas. 1993, 42, 7-13. [CrossRef]

67. Wang, X.; Yao, Y.; Zhao, S.; Jia, K.; Zhang, X.; Zhang, Y.; Zhang, L.; Xu, J.; Chen, X. MODIS-Based Estimation of Terrestrial Latent Heat Flux over North America Using Three Machine Learning Algorithms. Remote Sens. 2017, 9, 1326. [CrossRef]

68. Xu, T.; Guo, Z.; Xia, Y.; Ferreira, V.G.; Liu, S.; Wang, K.; Yao, Y.; Zhang, X.; Zhao, C.; Yao, Y. Evaluation of twelve evapotranspiration products from machine learning, remote sensing and land surface models over conterminous United States. J. Hydrol. 2019, 578, 124105. [CrossRef]

69. Huang, F.; Xie, G.; Xiao, R.X.R. Research on Ensemble Learning. In Proceedings of the 2009 International Conference on Artificial Intelligence and Computational Intelligence, Shanghai, China, 7-8 November 2009; pp. 248-252.

70. Ren, Y.; Zhang, L.; Suganthan, P. Ensemble Classification and Regression-Recent Developments, Applications and Future Directions. IEEE Comput. Intell. Mag. 2016, 11, 41-53. [CrossRef]

71. Sagi, O.; Rokach, L. Ensemble learning: A survey. Wiley Interdiscip. Rev. Data Min. Knowl. Discov. 2018, 8, 4. [CrossRef]

72. Wang, Y.; Wang, L. The Nonlinear Regression Based on BP Artificial Neural Network. Comput. Eng. Appl. 2004, 40, 79-82.

73. Srivastava, P.K.; Han, D.; Rico-Ramirez, M.A.; Islam, T. Machine Learning Techniques for Downscaling SMOS Satellite Soil Moisture Using MODIS Land Surface Temperature for Hydrological Application. Water Resour. Manag. 2013, 27, 3127-3144. [CrossRef] 
74. Ghimire, S.; Deo, R.; Downs, N.J.; Raj, N. Global solar radiation prediction by ANN integrated with European Centre for medium range weather forecast fields in solar rich cities of Queensland Australia. J. Clean. Prod. 2019, 216, 288-310. [CrossRef]

75. Zhang, C.; Denka, S.; Cooper, H.; Mishra, D.R. Quantification of sawgrass marsh aboveground biomass in the coastal Everglades using object-based ensemble analysis and Landsat data. Remote Sens. Environ. 2018, 204, 366-379. [CrossRef]

76. Kim, S.-H.; Cho, D.; Seok, K.-H. Study on the ensemble methods with kernel ridge regression. J. Korean Data Inf. Sci. Soc. 2012, 23, 375-383. [CrossRef]

77. Yuan, H.; Yang, G.; Li, C.-C.; Wang, Y.; Liu, J.; Yu, H.; Feng, H.; Xu, B.; Zhao, X.; Yang, X. Retrieving Soybean Leaf Area Index from Unmanned Aerial Vehicle Hyperspectral Remote Sensing: Analysis of RF, ANN, and SVM Regression Models. Remote Sens. 2017, 9, 309. [CrossRef]

78. Awange, J.L.; Ferreira, V.G.; Forootan, E.; Khandu; Andam-Akorful, S.; Agutu, N.; He, X. Uncertainties in remotely sensed precipitation data over Africa. Int. J. Clim. 2015, 36, 303-323. [CrossRef]

79. Chin, T.M.; Gross, R.S.; Dickey, J.O. Multi-Reference evaluation of uncertainty in earth orientation parameter measurements. J. Geodesy 2005, 79, 24-32. [CrossRef]

80. Liu, J.; Chai, L.; Lu, Z.; Liu, S.; Qu, Y.; Geng, D.; Song, Y.; Guan, Y.; Guo, Z.; Wang, J.; et al. Evaluation of SMAP, SMOS-IC, FY3B, JAXA, and LPRM Soil Moisture Products over the Qinghai-Tibet Plateau and Its Surrounding Areas. Remote Sens. 2019, 11, 792. [CrossRef]

81. Cronin, M.F.; Fairall, C.W.; McPhaden, M. An assessment of buoy-derived and numerical weather prediction surface heat fluxes in the tropical Pacific. J. Geophys. Res. Space Phys. 2006, 111, 6. [CrossRef]

82. Aytug, H.; Bhattacharyya, S.; Koehler, G.; Snowdon, J. A review of machine learning in scheduling. IEEE Trans. Eng. Manag. 1994, 41, 165-171. [CrossRef]

83. Zhang, C.; Zhang, J. A Survey of Selective Ensemble Learning Algorithms. Chin. J. Comput. 2011, 34, 1399-1410. [CrossRef]

84. Yao, Y.; Liang, S.; Li, X.; Zhang, Y.; Chen, J.; Jia, K.; Zhang, X.; Fisher, J.; Wang, X.; Zhang, L.; et al. Estimation of high-resolution terrestrial evapotranspiration from Landsat data using a simple Taylor skill fusion method. J. Hydrol. 2017, 553, 508-526. [CrossRef]

85. Kalma, J.D.; McVicar, T.R.; McCabe, M.F. Estimating Land Surface Evaporation: A Review of Methods Using Remotely Sensed Surface Temperature Data. Surv. Geophys. 2008, 29, 421-469. [CrossRef]

86. Li, X.; Wang, Y. Prospects on future developments of quantitative remote sensing. Acta Geogr. Sin. 2013, 68, $1163-1169$.

87. Wu, X.; Xiao, Q.; Wen, J.; Liu, Q.; Peng, J.; Li, X. Advances in uncertainty analysis for the validation of remote sensing products: Take leaf area index for example. J. Remote Sens. 2014, 18, 1011-1023. 